\title{
Evaluation-oriented exploration of photo energy conversion systems: from fundamental optoelectronics and material screening to the combination with data science
}

\author{
Akinori Saeki $\mathbb{1}^{1}$ \\ Received: 30 June 2020 / Revised: 28 July 2020 / Accepted: 29 July 2020 / Published online: 28 August 2020 \\ (c) The Author(s) 2020. This article is published with open access
}

\begin{abstract}
Light is a form of energy that can be converted to electric and chemical energies. Thus, organic photovoltaics (OPVs), perovskite solar cells (PSCs), photocatalysts, and photodetectors have evolved as scientific and commercial enterprises. However, the complex photochemical reactions and multicomponent materials involved in these systems have hampered rapid progress in their fundamental understanding and material design. This review showcases the evaluation-oriented exploration of photo energy conversion materials by using electrodeless time-resolved microwave conductivity (TRMC) and materials informatics (MI). TRMC with its unique options (excitation sources, environmental control, frequency modulation, etc.) provides not only accelerated experimental screening of OPV and PSC materials but also a versatile route toward shedding light on their charge carrier dynamics. Furthermore, MI powered by machine learning is shown to allow extremely high-throughput exploration in the large molecular space, which is compatible with experimental screening and combinatorial synthesis.
\end{abstract}

\section{Introduction}

$\pi$-Electrons that mostly occupy the highest occupied molecular orbital (HOMO) and the lowest unoccupied molecular orbital (LUMO) of aromatic compounds are of particular interest because they exhibit intriguing responses to external stimuli such as photons, electric fields, and magnetic fields [1-3]. Electronic excitation by a photon with an energy greater than the HOMO-LUMO gap (bandgap, $E_{\mathrm{g}}$ ) generates an exciton (a pair of holes and electrons coupled with phonons), the energy of which can be converted to electricity when the exciton is dissociated into free charge carriers (hole and electron) that are separately transported to the respective electrodes [4-6]. However, the exciton binding energy of a $\pi$-conjugated material is much larger than the thermal energy at room temperature due to the small dielectric constant, whereas an inorganic semiconductor undergoes prompt charge separation owing to

Akinori Saeki

saeki@chem.eng.osaka-u.ac.jp

1 Department of Applied Chemistry, Graduate School of Engineering, Osaka University, Suita 565-0871, Japan its large dielectric constant and small effective mass of charges [7, 8]. Accordingly, organic photovoltaics (OPVs) require a bulk heterojunction (BHJ) structure composed of a bicontinuous network of electron donor and acceptor materials (positive [p] and negative [n] semiconductors, respectively), which offers an energetic driving force for efficient charge separation at the enlarged interfacial area $[9,10]$.

Since the power conversion efficiency (PCE) of a solar cell is defined by the product of the short-circuit current density $\left(J_{\mathrm{SC}}\right)$, open-circuit voltage $\left(V_{\mathrm{OC}}\right)$, and fill factor $(\mathrm{FF})$ $\left[\mathrm{PCE}=J_{\mathrm{SC}} \times V_{\mathrm{OC}} \times \mathrm{FF}\left(P_{\text {in }}\right)^{-1}\right.$, where $P_{\text {in }}$ is the incident sunlight power density, typically $100 \mathrm{~mW} \mathrm{~cm}^{-2}$ of the pseudo-sunlight: air mass 1.5 global (AM1.5G)], maximizing all of these parameters is a direct way to improve PCE; however, $J_{\mathrm{SC}}$ and $V_{\mathrm{OC}}$ are inversely related because of the interplay among the bandgap excitation, sunlight spectrum, and electrochemical property. Shockley and Queisser calculated the PCE limit to be $\sim 33 \%$ for a single $\mathrm{p}-\mathrm{n}$ junction solar cell at $E_{\mathrm{g}} \sim 1.3 \mathrm{eV}$ [11], while the optimal $E_{\mathrm{g}}$ shifts to a larger value when the energy loss becomes large like OPV due to its large exciton binding energy, nonradiative charge recombination, energy offset to ensure charge separation, etc. [12-15]. The design of OPV materials is therefore complicated, as shown in Fig. 1, where 


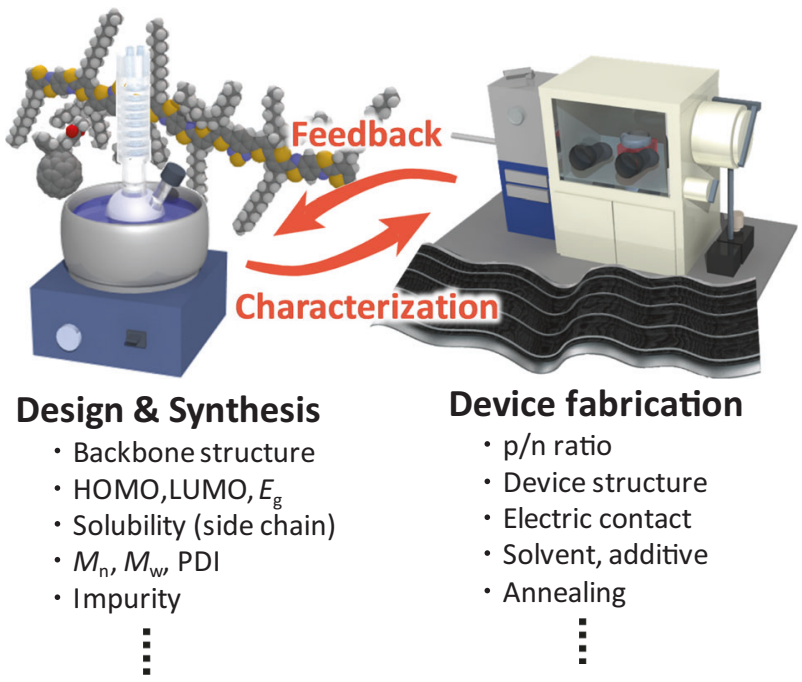

Fig. 1 Schematic of OPV development consisting of (left panel) material design and synthesis and (right panel) device fabrication and characterization, which includes various factors to be considered as listed below the image

both the backbone structure, which predominantly determines its HOMO, LUMO, and $E_{\mathrm{g}}$, and the side chains, which are associated with solubility and BHJ morphology, have a great impact on the device performance. In the case of $\pi$-conjugated polymers, their molecular weights (the number-averaged molecular weight, $M_{\mathrm{n}}$, and the weightaveraged molecular weight, $M_{\mathrm{w}}$ ) and polydispersity indices (PDIs) are closely related to the crystallinity and miscibility with an n-type semiconductor. Impurities such as residues of metal catalysts and target substituents for cross coupling polycondensation often act as charge traps, which should be removed as much as possible. Moreover, OPV device characterization requires tedious optimization of the $\mathrm{p} / \mathrm{n}$ blend ratio, device structure, solvent, additive, and thermal annealing. After the PCE reaches a maximum value for each conjugated material, feedback from the results is applied to the molecular design, and incremental modification and synthesis are performed. This kind of research cycle requires considerable time and effort, which precludes the rapid development of OPVs.

Time-resolved spectroscopies using an electromagnetic wave (EMW) as the probe can directly measure the dynamics of transient species (charge carriers, excitons, charge transfer complexes, etc.) that play key roles in the photoelectric conversion mechanism. These techniques include transient absorption spectroscopy (TAS) [16-18] and photoluminescence lifetime spectroscopy (PLS) [1921] using ultraviolet (UV)-visible (VIS)-infrared (IR) light pulses [the frequency is sub- $\mathrm{PHz}\left(10^{15} \mathrm{~s}^{-1}\right)$ ], time-domain terahertz $\left(10^{12} \mathrm{~s}^{-1}\right)$ spectroscopy (TD-THz) [22-24], and time-resolved microwave conductivity (TRMC) using gigahertz $\left(10^{9} \mathrm{~s}^{-1}, \mathrm{GHz}\right)$ microwaves [25-30]. Electron paramagnetic resonance (or electron spin resonance) $[31,32]$ and nuclear magnetic resonance $[33,34]$ using $\mathrm{GHz}$ and $\mathrm{MHz}\left(10^{6} \mathrm{~s}^{-1}\right)$ EMWs, respectively, in the presence of an external magnetic field provide partial information linked to the dynamic behaviors of molecules and short-lived species. A pulsed X-ray [its frequency is $\mathrm{EHz}\left(10^{18} \mathrm{~s}^{-1}\right)$ ] from a free electron laser is currently used to study ultrafast structural dynamics $[35,36]$. Owing to the high transmittances of EMWs in a free space (vacuum, air, and gas), these spectroscopies allow electrodeless measurements, in contrast to normal contact-mode measurements such as device characterization and $\mathrm{MHz}$ impedance spectroscopy that require metal electrodes to apply voltage and/or extract charges from a semiconductor. Having considered the photon energies of EMWs and their photophysical interaction with matter, TAS and PLS using UV-VIS-IR light reveal rich insight into the electronic transitions and vibrational motion of chemical bonds specific to transient species, while $\mathrm{GHz}$ and $\mathrm{THz}$ spectroscopies provide insight into the local oscillation motion of charges and rotational motion of dipoles. TAS and TD-THz with femtosecond time resolution require an expensive femtosecond laser system, an expertized setup of optics, and long-term averaging to obtain a very small signal, whereas TRMC using $\mathrm{GHz}$ EMW utilizes a relatively inexpensive excitation source (e.g., a nanosecond laser), an easy circuit setup, and a high-sensitivity resonant cavity. In addition, scattering of EMW, which is significant in UV-VIS light incident on a rough surface sample, is negligible in the $\mathrm{GHz}$ region; thus, TRMC is compatible with various forms of samples, including films, powders, liquids, and gases, but not with highly conductive materials (metals and highly doped semiconductors) and dipole-rich condensed matter (e.g., water).

Based on the unique interaction of $\mathrm{GHz}$ EMW with matter and its instrumental advantages, the author has developed a TRMC system for the evaluation of photo energy conversion materials. This review describes the fundamentals of $\mathrm{GHz}$ spectroscopy and its application to a study on material science.

\section{Basic of TRMC}

Figure 2a shows a schematic of a TRMC system, where the rectangular component with gold (yellow) color represents a resonant cavity (generally a transverse electric mode of $\mathrm{TE}_{102}$ ) containing a sample. The microwave circuit consists of a resonant cavity, a microwave source (a Gunn oscillator or a microwave generator), an isolator, (an attenuator), a circulator, a microwave amplifier, and a microwave detector. For a flash-photolysis (FP)-TRMC measurement using a UV-VIS-IR light pulse as the excitation, the transient 
(a) Oscilloscope

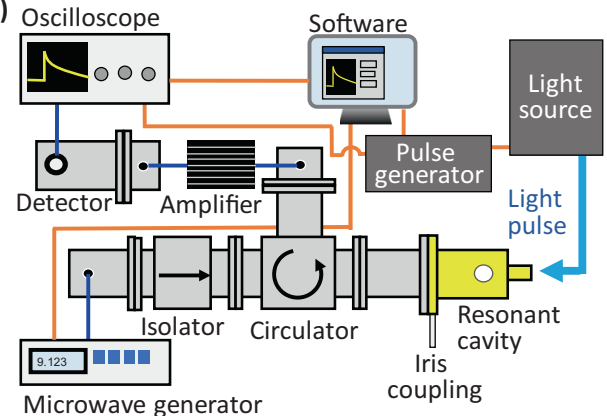

(b)

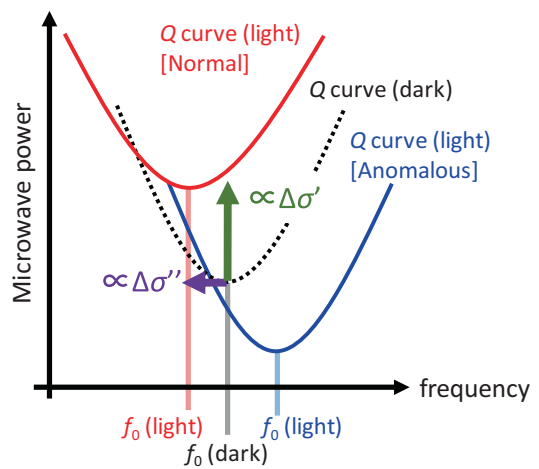

Fig. 2 a Schematic of a TRMC system. The component in gold color is a resonant cavity. The pipes attached to the cavity are used to introduce excitation light and a sample while confining the microwave inside. b Schematic of the change in the $Q$ curve at an undercoupling condition (see Eq. (3)). The dotted line represents the $Q$ curve in darkness, the red solid curve on the upper side represents the normal transient $Q$ curve upon light exposure [40], and the blue solid curve on the lower side represents an anomalous transient $Q$ curve upon light exposure [48]. Shifts in the vertical (microwave power) and horizontal (resonant frequency) directions correspond to the real $\left(\Delta \sigma^{\prime}\right)$ and imaginary $\left(\Delta \sigma^{\prime \prime}\right)$ components of photoconductivity, respectively (usually I $\left.\Delta \sigma^{\prime}|\gg| \Delta \sigma^{\prime \prime} \mid\right)$

photoconductivity $(\Delta \sigma)$ induced by photogenerated charge carriers is quantified by $[37,38]$

$\Delta \sigma=\frac{1}{A} \frac{\Delta P_{\mathrm{r}}}{P_{\mathrm{r}}}$

$A=\frac{\mp Q\left(1 / \sqrt{R_{0}} \pm 1\right)}{\pi f_{0} \varepsilon_{0} \varepsilon_{\mathrm{r}}}$,

where $A, \Delta P_{\mathrm{r}}$, and $P_{\mathrm{r}}$ are the sensitivity factor, the small change in the microwave power reflected from the resonant cavity upon photoexcitation, and the microwave power reflected from the resonant cavity in the dark, respectively. $R_{0}$ is the ratio of the reflected $\left(P_{\mathrm{r}}\right)$ and incident $\left(P_{\mathrm{i}}\right)$ microwave power $\left(R_{0}=P_{\mathrm{r}} / P_{\mathrm{i}}\right)$, and $\varepsilon_{\mathrm{r}}$ and $\varepsilon_{0}$ are the relative dielectric constant inside the cavity and the dielectric constant in vacuum, respectively. $f_{0}$ is the resonant frequency of the resonant cavity. $Q$ is the $Q$ (quality) value of the resonant cavity associated with the number of microwave reflections and the load in the cavity, which relates to the sensitivity of the measurement. Experimentally, $Q$ is estimated by $f_{0} / \Delta f_{1 / 2}$, where $\Delta f_{1 / 2}$ is the full bandwidth at half maximum of the reflected microwave power profile near $f_{0}$. The polarity $( \pm)$ of $A$ corresponds to the coupling condition ( + : undercoupling or - : overcoupling) of the waveguide and cavity, which can be tuned by an iris coupling equipped between the waveguide and the resonant cavity. Since $A$ is experimentally determined, a time evolution of $\Delta \sigma$ is readily obtained for each measurement. The power of the probing microwave is attenuated to a few to tens of milliwatts so that the electric field of the microwave neither disturbs the motion of charge carriers nor heats the sample (a microwave oven is a few hundred watts). As a trade-off of a highly sensitive resonant cavity, the measurement frequency is fixed for each microwave circuit, and the time resolution deteriorates to a few to one hundred nanoseconds, approximately given by $Q / f_{0}$.

Analogous to the rheology of viscoelastic materials and the complex refractive index of optics, the $\Delta \sigma$ obtained in $\mathrm{GHz}$ and $\mathrm{THz}$ spectroscopies is in a complex form composed of real $\left(\Delta \sigma^{\prime}\right)$ and imaginary $\left(\Delta \sigma^{\prime \prime}\right)$ components at a given frequency $(f) . \Delta \sigma^{\prime}$ and $\Delta \sigma^{\prime \prime}$ correspond to the small changes in the imaginary $\left(\Delta \varepsilon^{\prime \prime}\right)$ and real $\left(\Delta \varepsilon^{\prime}\right)$ parts of complex permittivity, respectively, through $\Delta \sigma^{\prime}=\varepsilon_{0} \omega \Delta \varepsilon^{\prime \prime}$ and $\Delta \sigma^{\prime \prime}=-\varepsilon_{0} \omega \Delta \varepsilon^{\prime}$, where $\omega$ is the angular frequency $(=2 \pi f)[39,40]$. Transient charge carriers generally cause an increase in a complex $\varepsilon\left(\Delta \varepsilon^{\prime}>0\right.$ and $\left.\Delta \varepsilon^{\prime \prime}>0\right)$, leading to a positive $\Delta \sigma^{\prime}$ and negative $\Delta \sigma^{\prime \prime}[40,41]$. The frequency dispersion of $\Delta \sigma(f)$ in the THz region is measured by TD-THz and often analyzed by a Drude-Smith model [42], whereas that in the $\mathrm{GHz}$ region measured by TRMC is not at one time due to the fixed resonant frequency. The formulas in Eqs. (1) and (2) correspond to the small change in the real part $\left(\Delta \sigma^{\prime}\right)$ associated with the dielectric loss, while the imaginary part $\left(\Delta \sigma^{\prime \prime}\right)$ appears as the transient change in the resonant frequency, as illustrated in Fig. 2b. The first perturbation theory of a resonant cavity leads to [39]

$\Delta\left(\frac{1}{Q}\right)-i \frac{2 \Delta \omega_{0}}{\omega_{0}}=\frac{F}{\varepsilon_{0} \omega_{0}}\left(\Delta \sigma^{\prime}-i \Delta \sigma^{\prime \prime}\right)$,

where $\Delta \omega_{0}$ and $F$ are the shift in the resonant angular frequency and the geometry factor considering the spatial overlap between the electric field and the sample in the resonant cavity. The second perturbation theory gives basically the same expression [43]. When $\Delta \sigma^{\prime}$ is small, $\Delta(1 / Q)$ in Eq. (3) is approximated to be proportional to $\Delta P_{\mathrm{r}} /$ $P_{\mathrm{r}}$, as given by Eq. (1), which is confirmed by a numerical calculation [44].

The real part of photoconductivity $\left(\Delta \sigma^{\prime}\right)$ is converted to the product of the quantum yield of charge carrier generation $(\varphi)$ and the sum of the charge carrier mobilities 
$(\Sigma \mu)\left(=\mu_{\mathrm{h}}+\mu_{\mathrm{e}}, \mu_{\mathrm{h}}\right.$ : hole mobility, $\mu_{\mathrm{e}}$ : electron mobility) by

$\varphi \sum \mu=\frac{1}{e \cdot I_{0} \cdot F_{\text {Light }}} \cdot \Delta \sigma$,

where $e, I_{0}$, and $F_{\text {Light }}$ are the unit charge of a single electron, the excitation photon density of the laser (photons $\left.\mathrm{cm}^{-2}\right)$ and the correction factor $\left(\mathrm{cm}^{-1}\right) . F_{\text {Light }}$ is calculated by homemade software that considers the sample geometry, the photoabsorption of the sample at the excitation wavelength, the laser spot and position, and the spatial overlap of the laser and electric field in a cavity calculated by an electrostatic simulation [44, 45]. Note that $\varphi$ and $\Sigma \mu$ are time-dependent when the disappearance of charges through recombination and trapping and charge relaxation are involved, respectively.

Considering the nanosecond time response of a resonant cavity, a nanosecond laser (typically $<10 \mathrm{~ns}$ in pulse width) such as a Nd:YAG (yttrium aluminum garnet) [the fundamental light: $1064 \mathrm{~nm}$, the second harmonic generation: $532 \mathrm{~nm}$, the third harmonic generation (THG): $355 \mathrm{~nm}$, the fourth harmonic generation: $266 \mathrm{~nm}$ ] and an optical parametric oscillator (e.g., 300-1000 nm) seeded by the THG of a Nd:YAG are usually used for excitation. These lasers emit monochromic light, while the performance of a solar cell is an overall electric output under exposure to broad-spectrum sunlight. As shown in Fig. 3, the author developed an excitation light source that utilizes a white light pulse from an in-house Xe-flash lamp, which is suitable for the evaluation of solar cell materials (vide infra) [46]. To gain mechanistic insight into charge transport, temperaturecontrolled experiments are performed in a vacuum chamber (a low temperature of $\sim 77 \mathrm{~K}$ to a high temperature of $\sim 400 \mathrm{~K}$ ), together with the change in gas (air, nitrogen, oxygen, etc.) in a closed cavity [47]. The most common microwave frequency of TRMC is $\mathrm{X}$ band $(\sim 9 \mathrm{GHz})$, while other frequencies such as the $\mathrm{K}_{\mathrm{u}}$ band $(\sim 15.4 \mathrm{GHz}), \mathrm{K}$ band $(\sim 22.9 \mathrm{GHz})$, and $\mathrm{Q}$ or $\mathrm{K}_{\mathrm{a}}$ band $(\sim 33.2 \mathrm{GHz})$ are available [40, 47, 48]. Moreover, measuring the photoconductivity transients at modulated frequencies near $f_{0}$ and reconstructing the transient $Q$ curves by means of in-house software enable the separation of $\Delta \sigma^{\prime}$ and $\Delta \sigma^{\prime \prime}$ on the basis of Eq. (3) [40, 41]. This evaluation can reveal the depth and density of charge traps [40] and anomalous dielectric behavior in organic-inorganic perovskites [48] (Fig. 2b). Although $\Delta \sigma$ and $\varphi \Sigma \mu$ arise from the local (nanometer scale) motion of charges and dipoles, these values are averaged over the exposed light spot (a few millimeters). Accordingly, a spatiotemporal option was developed by embedding an optical microscope that focuses the laser spot to $\sim 45 \mu \mathrm{m}$ in size [49]. Although the spatial resolution is too low to visualize the crystal grains of perovskite $(<1 \mu \mathrm{m})$, the measurement revealed the spatial inhomogeneity of $\Delta \sigma$ in halogen-mixed perovskite $\left[\mathrm{MAPb}\left(\mathrm{I}_{1-x} \mathrm{Br}_{x}\right)_{3}, \mathrm{MA}\right.$ :

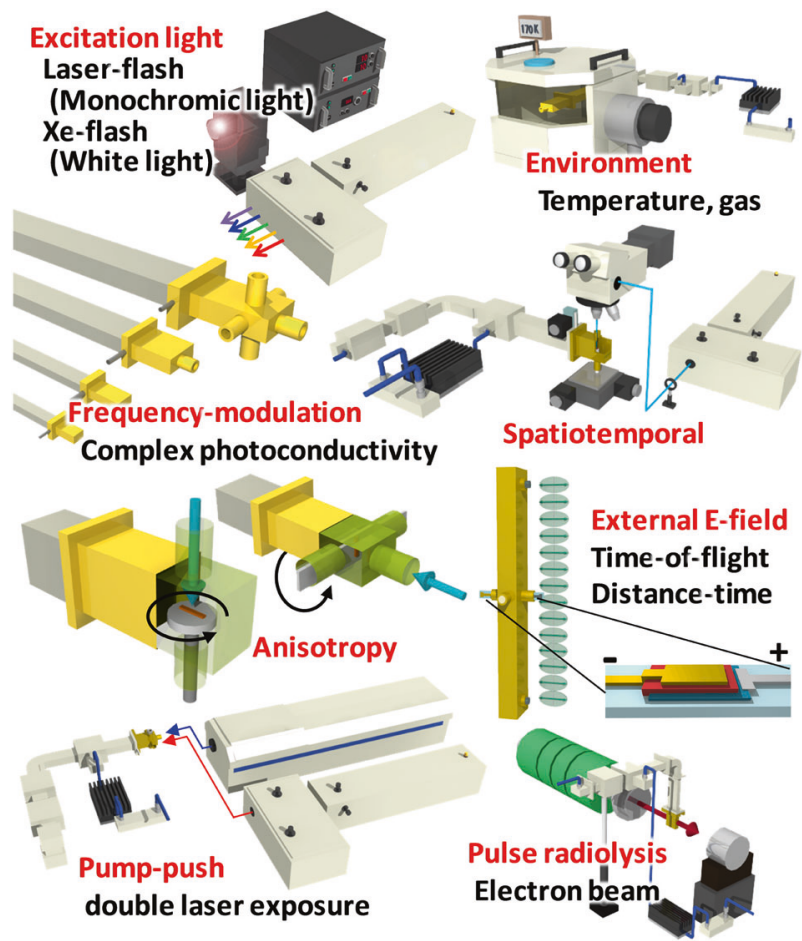

Fig. 3 Drawing of TRMC options that the author has developed

methylammonium cation] along the distance from the center of spin coating. In addition to an increased sensitivity of the resonant cavity, the direction of the electric field inside is fixed. Based on this property, anisotropic photoconductivity and mobility along various sample directions (parallel and perpendicular to a film and the $x y z$ axes of a crystal) are easily evaluated with a high angular resolution [50-62].

As a drawback of high-sensitivity resonant cavities, solar cell devices are incompatible with TRMC measurements because of the absorption and/or reflection of microwaves by the gold, aluminum, silver, or indium tin oxide electrodes in the devices. Nonetheless, charge carrier dynamics under not only open-circuit conditions (no electrodes) but also short-circuit conditions (charge extraction by electrodes) are of interest. The author developed a high-mode, long-shaped cavity $\left(\mathrm{TE}_{10 m}, m=14\right)$ that enables TRMC measurements of an OPV device by applying an external electric field [63]. By using this system, time-of-flight (TOF) and TRMC measurements were simultaneously conducted, which elucidated hole relaxation in spatial (nm$\mu \mathrm{m}$ ) and temporal ( $\mu$ s) aspects (vide infra). A pump-push measurement using a UV pump pulse and an IR push pulse from two laser systems has been developed and used to investigate a charge trap and its relaxation [48, 64]. Pulse radiolysis using a pulsed electron beam from a high-energy accelerator is an effective method for quantitative, homogeneous injection of charges in a solution and block sample [28, 37], whereas light injection has an uncertainty of $\varphi$ that depends on the sample, wavelength, intensity, and time 

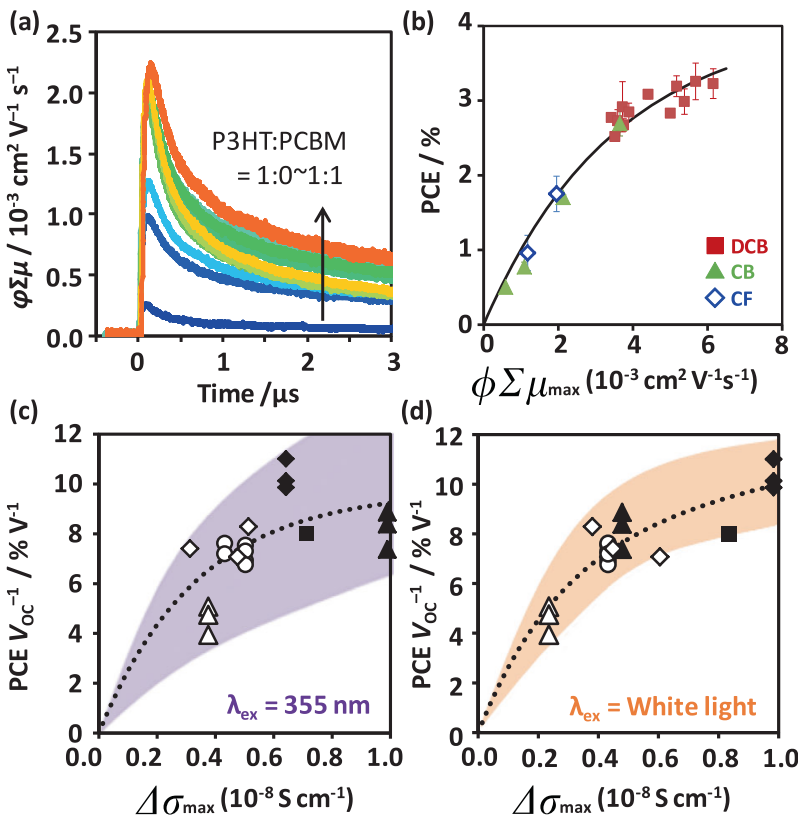

Fig. 4 TRMC evaluations of OPV films. a $\varphi \Sigma \mu$ transients of P3HT: PCBM with changing blend ratio (1:0 as the blue line to $1: 1$ as the orange line). The excitation wavelength $\left(\lambda_{\mathrm{ex}}\right)$ was $355 \mathrm{~nm}$. b PCE vs. $\varphi \Sigma \mu_{\max }$ of P3HT:PCBM (1:1) with different solvents (DCB, CB, CF) and thermal annealing temperatures. $\lambda_{\mathrm{ex}}=355 \mathrm{~nm}$. The solid line is a least-mean-square fitted inverse exponential function. $\mathbf{c} \mathrm{PCE} V_{\mathrm{OC}}{ }^{-1} \mathrm{vs}$. $\Delta \sigma_{\max }$ of NBPs:PCBM $\left(\lambda_{\mathrm{ex}}=355 \mathrm{~nm}\right)$. The circle, triangle, square, and diamond correspond to NBPs:PCDTBT, PCPDTBT, PBDTTPD, and PBDTTT-CF, respectively. The open and closed symbols are without additive and with 1,8-diiodooctane (DIO), respectively. d PCE $V_{\mathrm{OC}}{ }^{-1}$ vs. $\Delta \sigma_{\max }$ of NBPs:PCBM ( $\lambda_{\mathrm{ex}}=$ white light pulse). $\mathbf{a}, \mathbf{b}$ and $\mathbf{c}, \mathbf{d}$ are reproduced from [92] (Copyright: 2011 Wiley-VCH) and [46] (Copyright: 2012 American Chemical Society), respectively, with permission

range. Other notable TRMC options include field-induced TRMC [65], TRMC under pressure in a hydrostatic medium $(<0.15 \mathrm{GPa})$ [66], steady-state microwave conductivity using chopped light and a lock-in amplifier [67, 68], and spatiotemporal imaging of microwave conductivity [69], highlighting the diversity and versatility of $\mathrm{GHz}$ spectroscopies.

\section{Photoelectric conversion materials: OPVs, perovskite, and photocatalysts}

Owing to the electrodeless measurement of the local motions of charge carriers, laser-flash TRMC has been extensively used in liquid crystalline materials [55, 70-72], self-assembled nanostructures $[50,60,73-80]$, microcrystals [52, 56, 81-84], and liquids/gels [85-88], which are often associated with difficulties in preparing high-quality films suitable for device characterization, such as a fieldeffect transistor (FET). Although one can prepare a smooth film of a conjugated polymer, the $\varphi$ value of its pristine film is very small $\left(10^{-5}-10^{-3}\right)$ and unable to be determined solely by TRMC measurements. To address this issue, the author incorporated perylenebisimide (PBI) into a poly(3hexylthiophene) (P3HT) film, which acts both as an electron acceptor to increase $\varphi$ and as a spectroscopic probe to determine $\varphi[89,90]$, because the PBI radical anion has a characteristic photoabsorption and a large extinction coefficient at $\sim 720 \mathrm{~nm}$ [91]. From the simultaneous measurements of TRMC $(\varphi \Sigma \mu)$ and TAS $(\varphi)$, the TRMC hole mobilities $\left(\Sigma \mu \approx \mu_{\mathrm{h}}\right)$ in regioregular and regiorandom P3HT films were determined to be $\sim 0.1$ and $0.006 \mathrm{~cm}^{2} \mathrm{~V}^{-1} \mathrm{~s}^{-1}$, respectively [89]. Notably, the former was considerably decreased when a large amount of PBI (e.g., $>41$ wt $\%$ ) was mixed in due to the disturbed lamellar formation of P3HT.

A mixture of a donor and an acceptor is similar to the BHJ framework of OPVs, while soluble fullerenes $([6,6]$ phenyl- $\mathrm{C}_{61}$-butyric acid methyl ester: $\mathrm{PCBM}$ and $[6,6]-$ phenyl- $\mathrm{C}_{71}$-butyric acid methyl ester: $\mathrm{PC}_{71} \mathrm{BM}$ ) are commonly used as n-type semiconductors. The author next investigated the correlation of TRMC signals with OPV device performance. Figure $4 \mathrm{a}$ shows the $\varphi \Sigma \mu$ transients of regioregular P3HT films blended with PCBM upon exposure to $355 \mathrm{~nm}$ light [92]. With increasing PCBM content, the maximum $\varphi \Sigma \mu\left(\varphi \Sigma \mu_{\max }\right)$ at the time resolution limit increased considerably and reached $2.3 \times 10^{-3} \mathrm{~cm}^{2} \mathrm{~V}^{-1} \mathrm{~s}^{-1}$ at P3HT:PCBM $=1: 1$. A further increase in PCBM led to decreases in the $\varphi \Sigma \mu_{\max }$ and lifetimes of decays. Notably, the product of $\varphi \Sigma \mu_{\max }$ and the half lifetime $\left(\tau_{1 / 2}\right)$ indicated the distinct maximum at $\mathrm{p}: \mathrm{n}=1: 1$, which is the optimal blend ratio in P3HT:PCBM OPVs suggesting the importance of $\mu \tau_{1 / 2}$ in the device performance. The large $\varphi$ and $\Sigma \mu$ are related to the high density of photogenerated charge carriers and the high yields of charge separation/transport, respectively, while the large $\tau_{1 / 2}$ results in efficient charge transport and collection with minimal loss. By separately characterizing $\varphi$ and $\Sigma \mu$ in various narrow-bandgap polymers (NBPs) and PCBM blends, $\Sigma \mu$ associated with the crystallinity and crystallite size of the polymer domain was suggested to have a positive impact on charge separation [93]. A large local mobility is presumably a key factor that facilitates charge separation to break the strong Coulombic potential of intermolecular excitons [21, 94, 95].

TRMC evaluations are useful for screening not only p:n ratios but also process conditions. Figure $4 \mathrm{~b}$ shows the plot of PCE vs. $\varphi \sum \mu_{\max }$ of different solvents (DCB: orthodichlorobenzene, $\mathrm{CB}$ : chlorobenzene, and $\mathrm{CF}$ : chloroform) and thermal annealing (no annealing and annealing at $140-160{ }^{\circ} \mathrm{C}$ ) found in P3HT:PCBM $=1: 1$ films (the excitation is $355 \mathrm{~nm}$ ) [92]. A pronounced, sublinear correlation was observed between PCE and $\varphi \Sigma \mu_{\max }$, demonstrating that TRMC allows rapid optimization of the process conditions without delicate fabrication of OPV devices. The addition of a Pd catalyst into P3HT:PCBM devices caused a 
significant drop in PCE (approximately half at $5 \mathrm{wt} \% \mathrm{Pd}$ ), whereas its effect on $\varphi \Sigma \mu_{\max }$ was marginal $(\sim 10 \%$ decrease), highlighting the tolerance of TRMC measurements against impurity and degradation (no change for 1 week of storage in air).

Despite the good correlation between TRMC and the OPV performances found in P3HT:PCBM, that in other NBP:PCBM films, deteriorated, as shown in Fig. 4c. This is because NBPs have variations in their photoabsorption, optimal film thickness, photocurrent generation, charge carrier lifetimes, etc. Scanning the excitation wavelength from UV to VIS to IR and integrating the results by considering the sunlight spectrum is technically possible but eliminates rapid measurement. Accordingly, the author developed a Xe-flash TRMC system using a white light pulse for excitation [46]. Good spectral matching of the white light pulses was confirmed by comparison with sunlight. The pulse width was tuned to $\sim 10 \mu$ s by considering the intensity of the TRMC signal and a typical transit time of charge carrier collection [96]. The decrease in time resolution $(\sim 10 \mu$ s for Xe-flash TRMC and $\sim 40 \mathrm{~ns}$ for laser-flash TRMC) is rather useful because the photoconductivity maximum $\left(\Delta \sigma_{\max }\right)$ of Xe-flash TRMC convolutes both $\varphi \Sigma \mu_{\max }$ and the lifetime (i.e., $\mu \tau_{1 / 2}$ value), and the light intensity of the white light pulse is much closer to that of sunlight than to that of a laser, allowing a direct comparison of this value $\left(\Delta \sigma_{\max }\right)$. The correlation of PCE $V_{\mathrm{OC}}{ }^{-1}$ with the $\Delta \sigma_{\max }$ values observed in NBPs (Fig. 4d) and p:n ratios (not shown in this article) is therefore improved, making Xe-flash TRMC versatile for material and process screening of OPV.

By using Xe- and laser-flash TRMC, new conjugated polymers for OPVs were explored. Benzobisthiazole (BBTz), shown in the left component of the polymer in Fig. 5a, is a weak electron acceptor but could act as a weak electron donor against strong electron acceptors. First, the author synthesized three random copolymers of $\mathrm{BBTz}$ coupled with benzothiadiazole (BT) or thienopyrroledione (TPD) as the acceptor and carbazole as the donor [97]. Although the solubilities of these polymers are insufficient due to the nonoptimized alkyl chains, TRMC evaluations of their PCBM blends were successfully performed, showing the largest $\Delta \sigma_{\max }$ for BBTz-BT. Based on this feedback, an alternating copolymer of BBTz-BT with branched long alkyl chains (identical to C12-DT in Fig. 5a) was synthesized and applied to OPV characterization. As a result, a high PCE of $6.5 \%$ was obtained, which established evaluation-oriented material exploration [98]. Second, the BT unit was modified by fluorinated BT [99], pyridine thiadiazole [99], and naphthobisthiadiazole (NTz) [100]. In the case of $\mathrm{NTz}$, six polymers with different combinations of alkyl chains were synthesized to examine their effects (Fig. 5a). TRMC screening of p:n ratios revealed that the optimal ratio is $\sim 1: 2$. Figure $5 \mathrm{~b}$ displays the $\Delta \sigma$ transients of
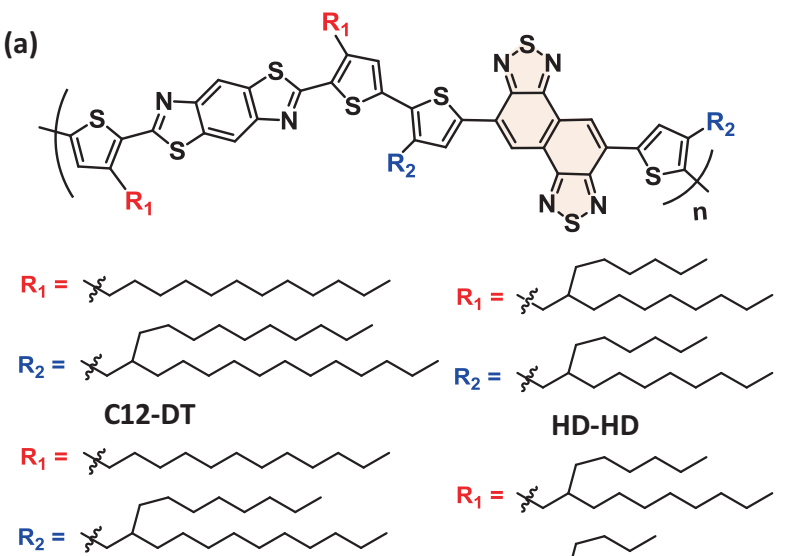

C12-OD

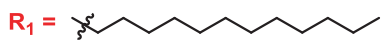

$R_{2}=3$

C12-HD

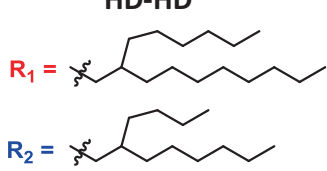

HD-BO

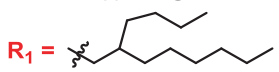

$R_{2}={ }_{3}$

BO-BO (b)

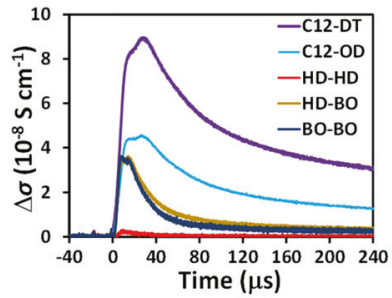

(c)

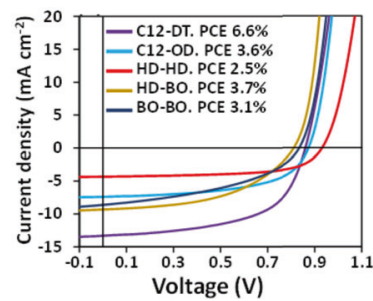

Fig. 5 a Chemical structures of PBBTzNTz polymers. b $\Delta \sigma$ transients of PBBTzNTz:PCBM films at their optimal blend ratios measured by Xe-flash TRMC ( $\lambda_{\mathrm{ex}}=$ white light pulse). Each decay corresponds to the respective alkyl chain. $\mathbf{c}$ Current density vs. voltage curves of the PBBTzNTz:PCBM devices. Their PCE values are appended. Reproduced from [100] with permission (Copyright: 2017 American Chemical Society)

different alkyl chains at their optimal p:n blend ratios. The $\Delta \sigma$ of the purple-colored profile (C12-DT) is the largest, followed by the white blue (C12-OD), dark blue (BO-BO) $=$ dark yellow (HD-BO), and red (HD-HD) profiles. The PCE values of these OPVs were exactly the same as those determined by the TRMC evaluations (Fig. 5c), where the maximum PCE of C12-DT was $6.6 \%$. The PCE variations despite the identical polymer backbone was attributed to their BHJ morphologies. C12-DT exhibited microfiber structures of polymer crystallites on the atomic force microscopy images, whereas the microfibers disappeared in $\mathrm{BO}-\mathrm{BO}$, and sphere-shaped aggregates were observed in the lowest-performing HD-HD. To date, no general rule on the design of side alkyl chains has been established; thus, researchers have to synthesize plausible combinations of alkyl chains for each backbone.

Despite rapid screening of OPV materials by TRMC, the experimental measurements require realistic materials. 
(a)

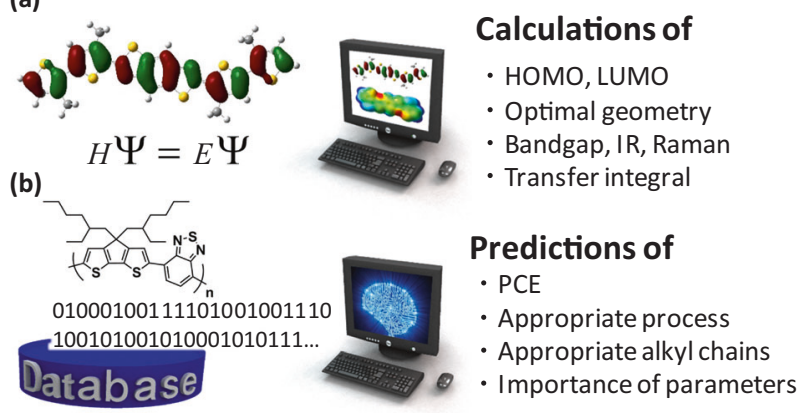

(c)

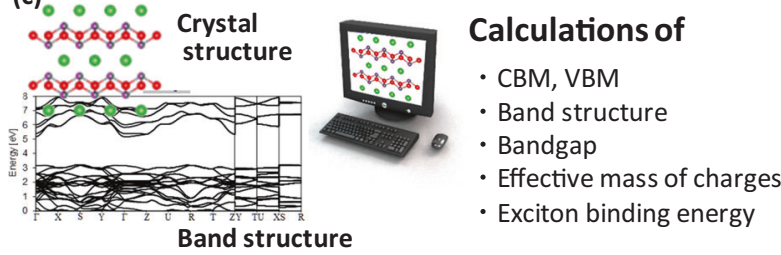

Fig. 6 Conceptual images of computer-aided evaluations and predictions. a Conventional quantum chemical calculations such as DFT. b ML-based prediction of OPV materials. c Quantum chemical calculations of inorganic semiconductors in band theory

Furthermore, a calculation-driven exploration of materials has become increasingly attractive over the past three decades [101-104] due to continuous improvements in computer hardware, software, and quantum chemical theory. Quantum chemical calculations such as density functional theory (DFT) together with Marcus electron transfer theory and molecular dynamics simulations enable a virtual evaluation of subjected molecules, which quantifies fundamental properties such as HOMO, LUMO, $E_{\mathrm{g}}$, a transfer integral, and mesoscale molecular conformations (Fig. 6a) [105]. However, these calculations are computationally expensive to obtain high-accuracy outputs. Irrespective of the high-cost calculations, these properties do not always correlate with the OPV performance because many multidimensional factors (solubility, intermolecular interactions, miscibility, solvent, etc.) affect the BHJ morphology and interfacial energetics in a complex manner. Along these lines, data science-a counterpart of computer science and empowered by ever-growing artificial intelligence-is rising to prominence as extremely high-throughput material screening. Accordingly, materials informatics (MI) utilizing machine learning (ML) technology has been deployed for inorganic thermoelectric materials [106, 107], inorganic semiconductors [108-110], and molecular drugs [111, 112]. For these materials, there is a relatively close relationship between the calculated values and material function because the electronic properties of a periodic framework of inorganic compounds or a single molecule exhibit a direct influence on their functions. Although MI-driven molecular exploration in organic electronics is challenging [104, 113115], attempts have been made in FET molecules
$[116,117]$, thermally activated delayed fluorescence molecules [118, 119], and OPV materials [120-123].

The author extended his research on experimental screening by TRMC to virtual screening by ML (Fig. 6b) [121]. An ML study needs a large database; however, such a database specific to OPV is unavailable, in contrast to well-compiled inorganic databases. Accordingly, OPV data ( 1200 entries from 500 papers) were manually collected from the literature, which includes the step-by-step pickup of OPV parameters (polymer:PCBM/PC ${ }_{71} \mathrm{BM}$ ) and physical properties $\left(M_{\mathrm{n}}, M_{\mathrm{w}}\right.$, PDI, $\left.E_{\mathrm{g}}, \mathrm{HOMO}, \mathrm{LUMO}\right)$ and conversion of chemical images to digital structures [a ChemDraw format and simplified molecular input line entry system (SMILES)]. The SMILES was then converted to a Boolean series by checking the 1024 digital numbers of an extended connectivity fingerprint (ECFP6) key of each chemical structure. ECFP6 is a high-resolution fingerprint that considers the neighboring connectivity of atoms and is calculated by the RDKit tool of R Studio (R language) or Anaconda (Python) software. ML with the random forest (RF) algorithm that uses multiple decision trees and averages all these outputs yielded a Pearson's correlation coefficient $(r)$ of 0.62 . Although this $r$ value is still unsatisfactory ( 1 for a perfect positive correlation), this $\mathrm{ML}$ allows rapid material screening ( $<1 \mathrm{~s}$ for 1000 structures) and a prediction of appropriate alkyl chains for each polymer backbone, which is impossible in conventional DFT calculations. In this ML, the chemical structures (ECFP6 keys) and physical properties $\left(M_{\mathrm{w}}, E_{\mathrm{g}}\right.$, etc.) of polymers were used as the input (explanatory variables), and PCE was set as the output (an objective variable), where the importance of the RF algorithm revealed that the most important explanatory variables were $M_{\mathrm{w}}, E_{\mathrm{g}}$, and some of the fingerprints. The choice of algorithm is also crucial to prediction accuracy; for example, an artificial neural network (ANN)—often used in image and voice recognitionresulted in a very low $r$ of 0.37 . This is possibly because RF is tolerant of noise data (incorrect or exceptional data) and leads to high accuracy even in a small dataset, whereas ANN requires a large dataset (>tens of thousands entries) with minimal noise data included. The ML study of polymer:fullerene acceptor (FA) was further evolved to polymer:nonfullerene (NFA) that recently demonstrated a remarkable improvement in PCE of up to 18\% [124-127]. The RF ML model of polymer:NFA ( $\sim 500$ entries) constructed in the same way as that of polymer:FA exhibited an improved $r$ of $0.85[128,129]$. This improvement is probably due to the almost doubled inputs (polymer and NFA data) and improved data accuracy reported in recent years. Surprisingly, this model showed good agreement between the predicted PCE (11.2\%) and the experimental PCE (11.0\%, average: $10.6 \pm 0.2 \%)$ for a new polymer and NFA [128]. Furthermore, the predicted appropriate alkyl chains 
(n-octyl or 2-ethylhexyl) and process conditions (solvent, additive, thermal annealing, and p:n blend ratio) were consistent with the experiments. These works open up an attractive avenue to the effective exploration of complex photoelectric systems from experimental and virtual spaces, which may be increasingly important in the recent paradigm shift caused by coronavirus outbreaks.

Vigorous investigations on blooming perovskite solar cells (PSCs) have been conducted by using TRMC techniques, including charge carrier dynamics [47, 130-134], charge transfer to hole and electron transfer layers assisted by data science analysis [135], and the development of leadfree materials (Sn $[48,136,137]$ and $\mathrm{Bi} / \mathrm{Sb}[138-140])$. The revealed TRMC mobilities $\left(10-100 \mathrm{~cm}^{2} \mathrm{~V}^{-1} \mathrm{~s}^{-1}\right)$ of lead halide perovskites $[47,134,135]$ are much larger than those of organic semiconductors $\left(0.1-1 \mathrm{~cm}^{2} \mathrm{~V}^{-1} \mathrm{~s}^{-1}\right)$ and account for the high PCE of PSCs. A unique GHz dielectric behavior ascribed to the rotational motion of organic cations is also notable [48]. In addition to these photoelectric conversion systems (OPV and PSC), inorganic photocatalysts that generate oxygen and/or hydrogen from water and sunlight energy are materials of interest. Based on knowledge obtained in the $\mathrm{GHz}$ dielectric behavior of PSC, the author directly probed the interplay of charge trap and elemental stoichiometry $(\mathrm{Sr} / \mathrm{Ti})$ of $\mathrm{SrTiO}_{3}$, a paraelectric perovskite used as the hydrogen-generating photocatalyst [141]. $\mathrm{Bi}_{4} \mathrm{TaO}_{8} \mathrm{Cl}$ and $\mathrm{PbBiO}_{2} \mathrm{Cl}$ photocatalysts [142] showed good correlation of $\varphi \Sigma \mu_{\max } \times \tau_{1 / 2}$ with their oxygen evolution rates, where $\varphi \Sigma \mu_{\max }$ increased monotonically with the calcination temperature due to the improved crystallinity evaluated by XRD, while $\tau_{1 / 2}$ decreased in line with the halogen defect found by X-ray photoelectron spectroscopy [143].

The complexity of photochemical reactions is significant in photocatalysts, as they involve photoabsorption, charge separation and transport, and oxidative/reductive reactions on the solid/liquid interface facilitated by cocatalysts. Nonetheless, one of the most primitive parameters of inorganic semiconductors in band theory is the effective mass of charge $\left(m^{*}\right)$, which is related to the mobility $(\mu)$ as follows (Fig. 6c) [144]:

$\mu=\frac{e \tau}{m *}$,

where $\tau$ is the collision (scattering, relaxation) time of the charge carrier. $m^{*}$ is calculated from the double partial differentials of the curvature in the band diagram given by [144]

$m *=\hbar^{2}\left(\frac{\partial^{2} E(k)}{\partial k^{2}}\right)^{-1}$, where $\hbar$ is the reduced Planck constant (the Dirac constant), $E(k)$ is the energy profile corresponding to the valence band maxima for a hole and conduction band minimum for an electron, and $k$ is the wavenumber. In band theory, the exciton binding energy $\left(E_{\text {bind }}\right)$ is estimated by the Rydberg equation for a hydrogen-like atom expressed by [144]

$E_{\text {bind }}=\frac{e^{4}}{2 \hbar^{2} \varepsilon^{2}} \frac{m_{\mathrm{e}^{2}} * m_{\mathrm{h}} *}{m_{\mathrm{e}} *+m_{\mathrm{h}} *}$,

where $m_{\mathrm{h}} *$ and $m_{\mathrm{e}} *$ are the effective masses of a hole and electron, respectively. From Eqs. (5-7), one can readily expect that a small effective mass of charge leads to a small $E_{\text {bind }}$ and a large $\mu$ that merit efficient charge separation, charge transport, and consequently the optoelectronic output. Furthermore, the relationship among the calculated $m^{*}$, experimental $\mu$, and photocatalytic activity has remained elusive because of the abovementioned complexity of photocatalytic systems. However, this relationship was revealed in $\mathrm{PbBiO}_{2} \mathrm{Cl}$ and $\mathrm{SrBiO}_{2} \mathrm{Cl}$ photocatalysts, where the mixing of $\mathrm{Sr}$ and $\mathrm{Pb}$ formed a solid solution at arbitrary ratios [62]. Both $m_{\mathrm{h}}{ }^{*}$ and $m_{\mathrm{e}}{ }^{*}$ calculated by DFT increased with increasing $\mathrm{Pb}$ content, which corresponded to decreases in $\varphi \sum \mu_{\max }$ (the change in $\tau_{1 / 2}$ is insignificant) and the oxygen evolution rate. Such a fundamental correlation was observed for the first time, owing to the continuous replacement of $\mathrm{Sr}$ by $\mathrm{Pb}$ and insignificant change in the particle morphology and crystal polymorph. Since $m^{*}$ is obtained by quantum chemical calculations or predicted by ML, this work encourages efficient exploration of potential semiconducting photocatalysts based on transient spectroscopies and computed parameters.

\section{Beyond ML: a regression to experiments}

ML allows the prediction of complex systems with acceptable accuracy by extremely high-speed screening over millions of candidates, which is impossible by human brains [101-104]. However, ML predictions have uncertainty and are biased on the learned data, including success and failure; thus, the author believes that experiences, inspirations, and serendipity of researchers are undoubtedly necessary for the substantial revolutions and breakthroughs that science has sometimes encountered in its history [145, 146]. Rapid TRMC screening of photoelectric materials is therefore a sound method to find a plausible candidate that has not yet been thoroughly explored. Figure 7 shows the logarithmic $\Delta \sigma_{\max }$ values of over 200 semiconductors (inorganic and organic/inorganic hybrids) measured by our Xe-flash TRMC. These values were sequentially measured when the materials were synthesized in the laboratory, bought 


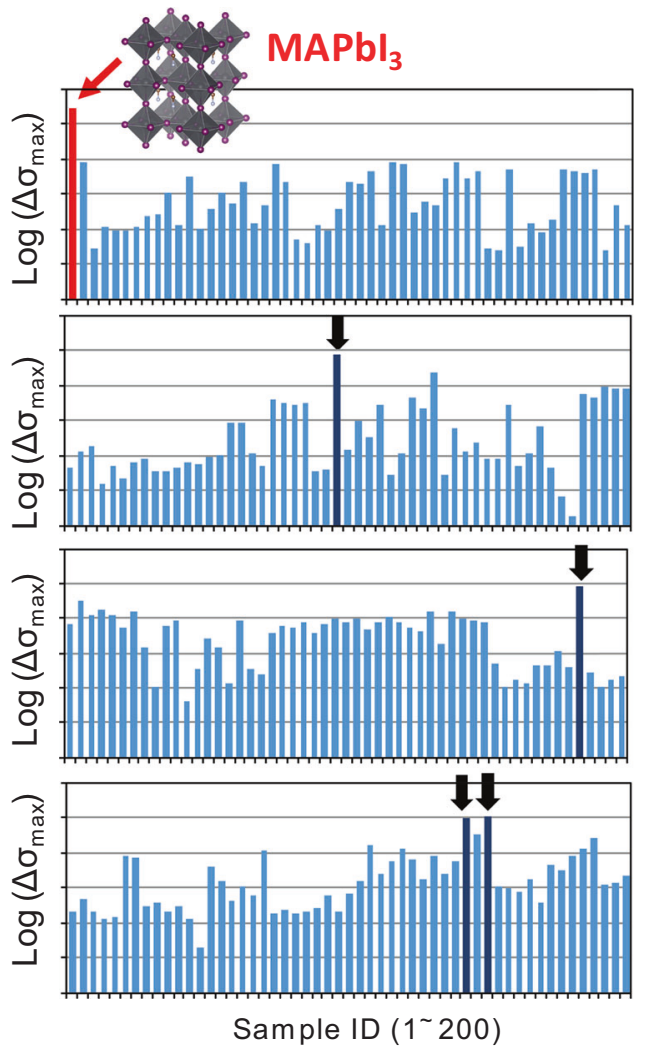

Fig. 7 Rapid experimental screening of inorganic and organic-inorganic hybrid semiconductors by using Xe-flash TRMC. The vertical axis is the common logarithmic plot of $\Delta \sigma_{\max }$ (arbitrary unit). The red bar represents the $\Delta \sigma_{\max }$ of the highly efficient perovskite of $\mathrm{MAPbI}_{3}$ along with its structure. The dark blue bar with arrows represents the materials that show relatively high $\Delta \sigma_{\max }$ values

from companies, and supplied from collaborators. The highly efficient organic-inorganic perovskite of $\mathrm{MAPbI}_{3}$ (red bar in the figure) exhibited a very high $\Delta \sigma_{\max }$ relevant to the high PCE of PSC devices. Most of the $\Delta \sigma_{\max }$ values of other semiconductors were, however, two to five orders of magnitude smaller than that of $\mathrm{MAPbI}_{3}$. Notably, four materials indicated by the dark blue arrows in the figure exhibited high $\Delta \sigma_{\max }$ values, although they were still one order of magnitude smaller than that of $\mathrm{MAPbI}_{3}$. One such material is bismuth sulfide $\left(\mathrm{Bi}_{2} \mathrm{~S}_{3}\right)$ powder, which is a twodimensional metal chalcogenide with a semiconductive nature [147, 148] but is mostly unexplored because of problems in preparing a high-quality film.

Despite the insoluble nature of $\mathrm{Bi}_{2} \mathrm{~S}_{3}$ in organic solvents, film fabrication is reportedly possible through colloidal nanocrystal suspension (NC) [149], chemical bath deposition [150], successive ionic layer adsorption reaction [151], spray pyrolysis [152], and a precursor of bismuth triethyldithiocarbonate (xanthate) $\left(\mathrm{Bi}(\mathrm{EtX})_{3}\right)$ [153]. However, these methods result in a trade-off between the electronic and morphological qualities, i.e., a film prepared by NC yields a smooth surface but a low crystallinity and a small size
[149]; a film prepared from $\mathrm{Bi}(\mathrm{EtX})_{3}$ yields high crystalline $\mathrm{Bi}_{2} \mathrm{~S}_{3}$ but contains rod-shaped morphologies [153]. Accordingly, the author developed a novel film preparation method named chemically assisted spin coating and crystallization (CASC) that solves this issue by separating the crystal nucleation (spin coating of a precursor solution) and growth (under diluted $\mathrm{H}_{2} \mathrm{~S}$ gas) steps [154]. Many process conditions (precursors, solvents, time and temperature of thermal annealing, flow of $\mathrm{H}_{2} \mathrm{~S}$ gas) were screened by monitoring the $\Delta \sigma_{\max }$ values of Xe-flash TRMC as a figure of merit. As a result, a high-quality $\mathrm{Bi}_{2} \mathrm{~S}_{3}$ film was successfully realized by the CASC method, which satisfies both a high electronic quality (Hall effect electron mobility $\sim 7$ $\left.\mathrm{cm}^{2} \mathrm{~V}^{-1} \mathrm{~s}^{-1}\right)$ and a low surface roughness $(1.7 \mathrm{~nm})$ with a large grain size $(<400 \mathrm{~nm})$. A photoresistor (photodetector) fabricated with this film exhibited a high detectivity of $1.7 \times 10^{11}$ Jones $\left(\mathrm{cm} \mathrm{Hz}^{1 / 2} \mathrm{~W}^{-1}\right)$ comparable to that of $\mathrm{MAPbI}_{3}$, along with a long-term stability ( $>3$ months). This work again exemplifies an effective research concept of evaluation-oriented exploration of photo energy conversion systems.

Providing a rationale for the structure-property-function relationship is essential for scientific progress; however, such logical thinking is currently difficult in ML, as it learns only about the relationship between input and output without considering causality (i.e., black box). Moreover, an idea on the development of a new measurement system arises from human thinking (what is a problem, what one wants to know, what is available as an instrumental component, etc.). Therefore, the author regards TRMC as a tool to investigate a scientific basis rather than just to screen materials and processes. To this end, the TOF-TRMC system was developed to investigate the charge carrier dynamics and relaxation on a local scale under an external voltage [63]. The TRMC decays ascribed to holes in NBP: PCBM blend films [poly(cyclopentadithiophene-benzothiadiazole):PCPDTBT, P3HT, and poly(quarterthiophenedifluorinated benzothiadiazole):PffBT4T, as shown in Fig. 8a], were accelerated by applying a voltage, as explained by the accelerated hole collection by the counter negatively biased electrode. By analyzing the transient photocurrent decays, TRMC decays, second-order charge recombination, and first-order trapping under an external electric field, the hole relaxation at the local scale probed by TRMC was deduced as a function of travel distance (Fig. 8b). The relaxation speed is significant in the order of PCPDTBT:PC ${ }_{71} \mathrm{BM}, \mathrm{P} 3 \mathrm{HT}: \mathrm{PCBM}$, and PffBT4T:PCBM, which is consistent with their TOF mobilities, crystalline natures (PCPDTBT: amorphous, P3HT: crystalline with an edge-on orientation, and PffBT4T: crystalline with a faceon orientation), and optimal thicknesses of the OPV devices (PCPDTBT: $\sim 100 \mathrm{~nm}$, P3HT: $\sim 200 \mathrm{~nm}$, and PffBT4T: $\sim 300 \mathrm{~nm}$ ). Explainability and consistency among various 
(a)

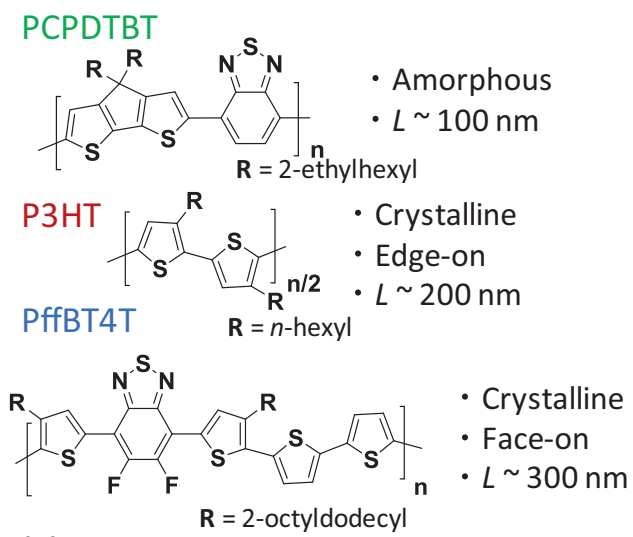

(b)

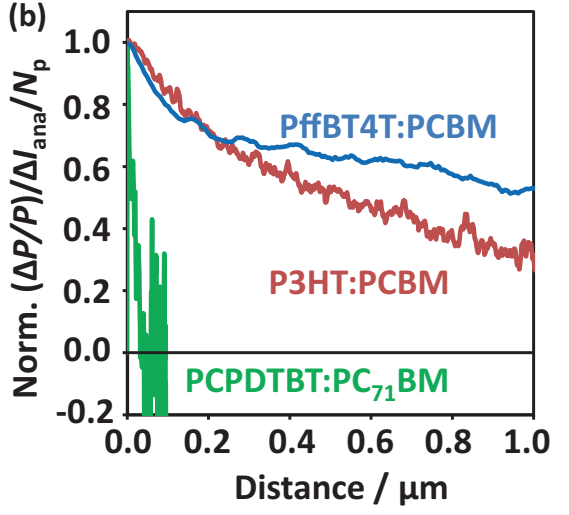

Fig. 8 a Chemical structures of OPV polymers used in the TOF-TRMC measurements. Their crystalline properties are appended with their optimal film thicknesses $(L)$ of OPV devices. b Normalized TRMC decay $(\Delta P / P)$ divided by analyzed photocurrent decay $\left(\Delta I_{\text {ana }}\right)$ and analytical curves considering bulk recombination and trap $\left(N_{\mathrm{p}}\right)$. Each curve shows the hole relaxation profile in the blend films along the travel distance of the hole. Reproduced from [63] with permission (Copyright: 2017 American Chemical Society)

measurements constitute the heart of science that should be pursued in the evaluation-oriented exploration of photo energy conversion systems.

\section{Concluding remarks}

This article reviewed the material exploration and fundamental research of photo energy conversion systems (OPVs, PSCs, photocatalysts, and photodetectors) based on noncontact-mode EMW spectroscopy (TRMC). The unique derivatives of this spectroscopy enable rapid screening of materials and processes suitable for solar cells (Xe-flash TRMC with a white light pulse), investigations of frequency dispersion and charge traps (frequency modulation), charge relaxation in time and distance (TOF-TRMC), and so on. In particular, a research concept combining molecular design and synthesis, TRMC evaluations, and ML-based prediction was demonstrated in the development of $\pi$-conjugated polymers for OPVs. The mobility-lifetime product $\left(\varphi \sum \mu_{\max } \times \tau_{1 / 2}\right)$ was found to be useful as a figure of merit, which is mostly general in OPV, PSC, and photocatalytic materials. The revealed correlation among $m^{*}, \varphi \Sigma \mu_{\max }$, and photochemical functions underscores the validity of computer and data science approaches, whereas the inspiration and serendipity of researchers are still pivotal for a discrete revolution of next-generation material science.

Acknowledgements The author greatly appreciates all of the collaborators and students involved in this study. This work was supported by the Precursory Research for Embryonic Science and Technology (PRESTO) programs (Photoelectric Conversion System: Grant No. 3905; Materials Informatics: Grant No. JPMJPR15N6) of the Japan Science and Technology Agency (JST); KAKENHI Grant-in-Aids for Scientific Research (Grant Nos JP16H02285 and 25288084), Young Scientists (Grant Nos 20686064 and 16760690), and Challenging Exploratory Research (Grant No. JP15K13816) of the Japan Society for the Promotion of Science (JSPS).

\section{Compliance with ethical standards}

Conflict of interest The author declares no conflict of interest.

Publisher's note Springer Nature remains neutral with regard to jurisdictional claims in published maps and institutional affiliations.

Open Access This article is licensed under a Creative Commons Attribution 4.0 International License, which permits use, sharing, adaptation, distribution and reproduction in any medium or format, as long as you give appropriate credit to the original author(s) and the source, provide a link to the Creative Commons license, and indicate if changes were made. The images or other third party material in this article are included in the article's Creative Commons license, unless indicated otherwise in a credit line to the material. If material is not included in the article's Creative Commons license and your intended use is not permitted by statutory regulation or exceeds the permitted use, you will need to obtain permission directly from the copyright holder. To view a copy of this license, visit http://creativecommons. org/licenses/by/4.0/.

\section{References}

1. Krygowski TM, Szatylowicz H, Stasyuk OA, Dominikowska J, Palusiak M. Aromaticity from the viewpoint of molecular geometry: application to planar systems. Chem Rev. 2014;114: 6383-422.

2. Islas R, Heine T, Merino G. The induced magnetic field. Acc Chem Res. 2012;45:215-28.

3. Tanaka K, Chujo Y. Modulation of the solid-state luminescent properties of conjugated polymers by changing the connecting points of flexible boron element blocks. Polym J. 2020;52: 555-66.

4. Ostroverkhova O. Organic optoelectronic materials: mechanisms and applications. Chem Rev. 2016;116:13279-412.

5. Osaka I. Semiconducting polymers based on electron-deficient $\pi$ building units. Polym J. 2015;47:18-25.

6. Tajima K. Look beyond the surface: recent progress in applications of surface-segregated monolayers for organic electronics. Polym J. 2019;51:1117-26. 
7. Dimitrov SD, Durrant JR. Materials design considerations for charge generation in organic solar cells. Chem Mater. 2014;26: 616-30.

8. Few S, Frost JM, Nelson J. Models of charge pair generation in organic solar cells. Phys Chem Chem Phys. 2015;17:2311-25.

9. Hiramoto M, Fujiwara H, Yokoyama M. Three-layered organic solar cell with a photoactive interlayer of codeposited pigments. Appl Phys Lett. 1991;58:1062-4.

10. Yu G, Gao J, Hummelen JC, Wudl F, Heeger AJ. Polymer photovoltaic cells: enhanced efficiencies via a network of internal donor-acceptor heterojunctions. Science. 1995;270:1789-91.

11. Shockley W, Queisser HJ. Detailed balance limit of efficiency of p-n junction solar cells. J Appl Phys. 1961;32:510-9.

12. Scharber MC, Mühlbacher D, Koppe M, Denk P, Waldauf C, Heeger AJ, et al. Design rules for donors in bulk-heterojunction solar cells-towards $10 \%$ energy-conversion efficiency. Adv Mater. 2006;18:789-94.

13. Hirst LC, Ekins-Daukes NJ. Fundamental losses in solar cells. Prog Photovolt. 2011;19:286-93.

14. Gruber M, Wagner J, Klein K, Hörmann U, Opitz A, Stutzmann M, et al. Thermodynamic efficiency limit of molecular donor-acceptor solar cells and its application to diindenoperylene/ $\mathrm{C}_{60}$-based planar heterojunction devices. Adv Energy Mater. 2012;2:1100-8.

15. Xie Y, Wang W, Huang W, Lin F, Li T, Liu S, et al. Assessing the energy offset at the electron donor/acceptor interface in organic solar cells through radiative efficiency measurements. Energy Environ Sci. 2019;12:3556-66.

16. Clarke TM, Durrant JR. Charge photogeneration in organic solar cells. Chem Rev. 2010;110:6736-67.

17. Baranovskii SD, Wiemer M, Nenashev AV, Jansson F, Gebhard F. Calculating the efficiency of exciton dissociation at the interface between a conjugated polymer and an electron acceptor. J Phys Chem Lett. 2012;3:1214-21.

18. Ohkita H, Tamai Y, Benten H, Ito S. Transient absorption spectroscopy for polymer solar cells. IEEE J Select Top Quantum Electron. 2016;22:4100612.

19. Chen K, Barker AJ, Reish ME, Gordon KC, Hodgkiss JM. Broadband ultrafast photoluminescence spectroscopy resolves charge photogeneration via delocalized hot excitons in polymer: fullerene photovoltaic blends. J Am Chem Soc. 2013;135: 18502-12.

20. Loi MA, Toffanin S, Muccini M, Forster M, Scherf U, Scharber M. Charge transfer excitons in bulk heterojunctions of a polyfluorene copolymer and a fullerene derivative. Adv Funct Mater. 2007;17:2111-6.

21. Veldman D, İpek Ö, Meskers SCJ, Sweelssen J, Koetse MM, Veenstra SC, et al. Compositional and electric field dependence of the dissociation of charge transfer excitons in alternating polyfluorene copolymer/fullerene blends. J Am Chem Soc. 2008; 130:7721-35.

22. Ai X, Beard MC, Knutsen KP, Shaheen SE, Rumbles G, Ellingson RJ. Photoinduced charge carrier generation in a poly (3-hexylthiophene) and methanofullerene bulk heterojunction investigated by time-resolved terahertz spectroscopy. J Phys Chem B. 2006;110:25462-71.

23. Bartelt AF, Strothkämper C, Schindler W, Fostiropoulos K, Eichberger R. Morphology effects on charge generation and recombination dynamics at $\mathrm{ZnPc}: \mathrm{C}_{60}$ bulk hetero-junctions using time-resolved terahertz spectroscopy. Appl Phys Lett. 2011;99: 143304.

24. Krauspe P, Tsokkou D, Causá M, Buchaca-Domingo E, Fei Z, Heeney $M$, et al. Terahertz short-range mobilities in neat and intermixed regions of polymer:fullerene blends with controlled phase morphology. J Mater Chem A. 2018;6:22301-9.
25. Saeki A, Tagawa S. Nanometer-scale dynamics of charges generated by radiations in condensed matter. Pure Appl Chem. 2009;81:45-60.

26. Saeki A, Koizumi Y, Aida T, Seki S. Comprehensive approach to intrinsic charge carrier mobility in conjugated organic molecules, macromolecules, and supramolecular architectures. Acc Chem Res. 2012;45:1193-202.

27. Seki S, Saeki A, Sakurai T, Sakamaki D. Charge carrier mobility in organic molecular materials probed by electromagnetic waves. Phys Chem Chem Phys. 2014;16:11093-113.

28. Grozema FC, Siebbeles LDA. Charge mobilities in conjugated polymers measured by pulse radiolysis time-resolved microwave conductivity: from single chains to solids. J Phys Chem Lett. 2011;2:2951-8.

29. Savenije TJ, Ferguson AJ, Kopidakis N, Rumbles G. Revealing the dynamics of charge carriers in polymer:fullerene blends using photoinduced time-resolved microwave conductivity. J Phys Chem C. 2013;117:24085-103.

30. Reid OG, Moore DT, Li Z, Zhao D, Yan Y, Zhu K, et al. Quantitative analysis of time-resolved microwave conductivity data. Phys D. 2017;50:493002.

31. Miura T, Tao R, Shibata S, Umeyama T, Tachikawa T, Imahori $\mathrm{H}$, et al. Geometries, electronic couplings, and hole dissociation dynamics of photoinduced electron-hole pairs in polyhexylthiophene-fullerene dyads rigidly linked by oligophenylenes. J Am Chem Soc. 2016;138:5879-85.

32. Thomson SAJ, Niklas J, Mardis KL, Mallares C, Samuel IDW, Poluektov OG. Charge separation and triplet exciton formation pathways in small-molecule solar cells as studied by timeresolved EPR spectroscopy. J Phys Chem C. 2017;121: 22707-19.

33. Etzold F, Howard IA, Forler N, Melnyk A, Andrienko D, Hansen $\mathrm{MR}$, et al. Sub-ns triplet state formation by non-geminate recombination in PSBTBT:PC ${ }_{70} \mathrm{BM}$ and PCPDTBT:PC ${ }_{60} \mathrm{BM}$ organic solar cells. Energy Environ Sci. 2015;8:1511-22.

34. Kubicki DJ, Hofstetter A, Emsley L, Prochowicz D, Pechy P, Zakeeruddin SM, et al. Cation dynamics in mixed-cation (MA) (FA) $)_{1-\mathrm{x}} \mathrm{PbI}_{3}$ hybrid perovskites from solid-state NMR. J Am Chem Soc. 2017;139:10055-61.

35. Jurek Z, Son S-K, Ziaja B, Santra R. XMDYN and XATOM: versatile simulation tools for quantitative modeling of $X$-ray freeelectron laser induced dynamics of matter. J Appl Crystallogr. 2016;49:1048-56.

36. Kling P, Sauerbrey R, Preiss P, Giese E, Endrich R, Schleich WP. Quantum regime of a free-electron laser: relativistic approach. Appl Phys B. 2017;123:1-14.

37. Infelta PP, de Haas MP, Warman JM. The study of the transient conductivity of pulse irradiated dielectric liquids on a nanosecond timescale using microwaves. Radiat Phys Chem. 1977;10:353-65.

38. de Haas MP, Warman JM. Photon-induced molecular charge separation studied by nanosecond time-resolved microwave conductivity. Chem Phys. 1982;73:35-53.

39. Slater JC. Microwave electronics. Rev Mod Phys. 1964;18: 441-512.

40. Saeki A, Yasutani Y, Oga H, Seki S. Frequency-modulated gigahertz complex conductivity of $\mathrm{TiO}_{2}$ nanoparticles: interplay of free and shallowly trapped electrons. J Phys Chem C. 2014;118:22561-72.

41. Saeki A, Seki S, Tagawa S. Electrodeless measurement of charge carrier mobility in pentacene by microwave and optical spectroscopy techniques. J Appl Phys. 2006;100:023703-8.

42. Smith NV. Classical generalization of the Drude formula for the optical conductivity. Phys Rev B. 2001;64:155106. 
43. Grabtchak S, Cocivera M. Microwave response due to lightinduced changes in the complex dielectric constant of semiconductors. Phys Rev B. 1998;58:4701-7.

44. Saeki A, Seki S, Sunagawa T, Ushida K, Tagawa S. Chargecarrier dynamics in polythiophene films studied by in-situ measurement of flash-photolysis time-resolved microwave conductivity (FP-TRMC) and transient optical spectroscopy (TOS). Philos Mag. 2006;86:1261-76.

45. Saeki A, Seki S, Koizumi Y, Tagawa S. Dynamics of photogenerated charge carrier and morphology dependence in polythiophene films studied by in-situ time-resolved microwave conductivity and transient absorption spectroscopy. J Photochem Photobiol A. 2007;186:158-65.

46. Saeki A, Yoshikawa S, Tsuji M, Koizumi Y, Ide M, Vijayakumar $\mathrm{C}$, et al. A versatile approach to organic photovoltaics evaluation using white light pulse and microwave conductivity. J Am Chem Soc. 2012;134:19035-42.

47. Oga H, Saeki A, Ogomi Y, Hayase S, Seki S. Improved understanding of the electronic and energetic landscapes of perovskite solar cells: high local charge carrier mobility, reduced recombination, and extremely shallow traps. J Am Chem Soc. 2014;136:13818-25.

48. Yamada K, Nishikubo R, Oga H, Ogomi Y, Hayase S, Kanno S, et al. Anomalous dielectric behavior of a $\mathrm{Pb} / \mathrm{Sn}$ perovskite: effect of trapped charges on complex photoconductivity. ACS Photonics. 2018;5:3189-97.

49. Caraballo F, Kumano M, Saeki A. Spatial inhomogeneity of methylammonium lead-mixed halide perovskite examined by space- and time-resolved microwave conductivity. ACS Omega. 2017;2:8020-6.

50. Yamamoto Y, Fukushima T, Jin W, Kosaka A, Hara T, Nakamura T, et al. A glass hook allows fishing of hexa-perihexabenzocoronene graphitic nanotubes: fabrication of a macroscopic fiber with anisotropic electrical conduction. Adv Mater. 2006;18:1297-300.

51. Saeki A, Seki S, Takenobu T, Iwasa Y, Tagawa S. Mobility and dynamics of charge carriers in rubrene single crystals studied by flash-photolysis microwave conductivity and optical spectroscopy. Adv Mater. 2008;20:920-3.

52. Hisaki I, Sakamoto Y, Shigemitsu H, Tohnai N, Miyata M, Seki $\mathrm{S}$, et al. Superstructure-dependent optical and electrical properties of an unusual face-to-face, $\pi$-stacked, one-dimensional assembly of dehydrobenzo[12]annulene in the crystalline state. Chem Eur J. 2008;14:4178-87.

53. Okamoto T, Nakahara K, Saeki A, Seki S, Oh JH, Akkerman $\mathrm{HB}$, et al. Aryl-perfluoroaryl substituted tetracene: induction of face-to-face $\pi-\pi$ stacking and enhancement of charge carrier properties. Chem Mater. 2011;23:1646-9.

54. Babu SS, Saeki A, Seki S, Möhwald H, Nakanishi T. Millimetersized flat crystalline sheet architectures of fullerene assemblies with anisotropic photoconductivity. Phys Chem Chem Phys. 2011:13:4830-4.

55. Yeh M-C, Su Y-L, Tzeng M-C, Ong CW, Kajitani T, Enozawa $\mathrm{H}$, et al. Amphiphilic design of a discotic liquid-crystalline molecule for dipole manipulation: hierarchical columnar assemblies with a 2D superlattice structure. Angew Chem Int Ed. 2013;52:1031-4.

56. Shigemitsu H, Hisaki I, Kometani E, Yasumiya D, Sakamoto Y, Osaka K, et al. Crystalline supramolecular nanofibers based on dehydrobenzoannulene derivatives. Chem Eur J. 2013;19: 15366-77.

57. Wakamiya A, Nishimura H, Fukushima T, Suzuki F, Saeki A, Seki S, et al. On-top $\pi$-stacking of quasiplanar molecules in holetransporting materials: inducing anisotropic carrier mobility in amorphous films. Angew Chem Int Ed. 2014;53:5800-4.
58. Wu L, Ohtani M, Takata M, Saeki A, Seki S, Ishida Y, et al. Magnetically induced anisotropic orientation of graphene oxide locked by in situ hydrogelation. ACS Nano. 2014;8:4640-9.

59. Leung FK-C, Ishiwari F, Kajitani T, Shoji Y, Hikima T, Takata $M$, et al. Supramolecular scaffold for tailoring the twodimensional assembly of functional molecular units into organic thin films. J Am Chem Soc. 2016;138:11727-33.

60. Ghosh S, Philips DS, Saeki A, Ajayaghosh A. Nanosheets of an organic molecular assembly from aqueous medium exhibit high solid-state emission and anisotropic charge-carrier mobility. Adv Mater. 2017;29:1605408.

61. Nakamura T, Shioya N, Shimoaka T, Nishikubo R, Hasegawa T, Saeki A, et al. Molecular orientation change in naphthalene diimide thin films induced by removal of thermally cleavable substituents. Chem Mater. 2019;31:1729-37.

62. Suzuki H, Kanno S, Hada M, Abe R, Saeki A. Exploring the relationship between effective mass, transient photoconductivity, and photocatalytic activity of $\mathrm{Sr}_{x} \mathrm{~Pb}_{1-x} \mathrm{BiO}_{2} \mathrm{Cl}(x=0-1)$ oxyhalides. Chem Mater. 2020;32:4166-73.

63. Shimata Y, Saeki A. Hole relaxation in polymer:fullerene solar cells examined by the simultaneous measurement of time-offlight and time-resolved microwave conductivity. J Phys Chem C. 2017;121:18351-9.

64. Yamada K, Saeki A. Photoconductivity of $\mathrm{Pb}-\mathrm{Sn}$ perovskite induced by UV pump and IR push pulses. J Photopolym Sci Technol. 2018;31:157-62.

65. Honsho Y, Miyakai T, Sakurai T, Saeki A, Seki S. Evaluation of intrinsic charge carrier transport at insulator-semiconductor interfaces probed by a non-contact microwave-based technique. Sci Rep. 2013;3:3182.

66. Noguchi Y, Saeki A, Fujiwara T, Yamanaka S, Kumano M, Sakurai T, et al. Pressure modulation of backbone conformation and intermolecular distance of conjugated polymers toward understanding the dynamism of $\pi$-figuration of their conjugated system. J Phys Chem B. 2015;119:7219-30.

67. Labram JG, Perry EE, Venkatesan NR, Chabinyc ML. Steadystate microwave conductivity reveals mobility-lifetime product in methylammonium lead iodide. Appl Phys Lett. 2018;113: 153902.

68. Blackburn JL, Zhang H, Myers AR, Dunklin JR, Coffey DC, Hirsch RN, et al. Measuring photoexcited free charge carriers in mono- to few-layer transition-metal dichalcogenides with steadystate microwave conductivity. J Phys Chem Lett. 2020;11: 99-107.

69. Chu Z, Wang CY, Quan J, Zhang C, Lei C, Han A, et al. Unveiling defect-mediated carrier dynamics in monolayer semiconductors by spatiotemporal microwave imaging. Proc Natl Acad Sci USA. 2020;117:13908-13.

70. Sakurai T, Shi K, Sato H, Tashiro K, Osuka A, Saeki A, et al. Prominent electron transport property observed for triply fused metalloporphyrin dimer: directed columnar liquid crystalline assembly by amphiphilic molecular design. J Am Chem Soc. 2008;130:13812-3.

71. Li W-S, Yamamoto Y, Fukushima T, Saeki A, Seki S, Tagawa $\mathrm{S}$, et al. Amphiphilic molecular design as a rational strategy for tailoring bicontinuous electron donor and acceptor arrays: photoconductive liquid crystalline oligothiophene- $\mathrm{C}_{60}$ dyads. $\mathrm{J}$ Am Chem Soc. 2008;130:8886-7.

72. Motoyanagi J, Yamamoto Y, Saeki A, Alam MA, Kimoto A, Kosaka A, et al. Unusual side-chain effects on charge-carrier lifetime in discotic liquid crystals. Chem Asian J. 2009;4: 876-80.

73. Yamamoto Y, Fukushima T, Suna Y, Ishii N, Saeki A, Seki S, et al. Photoconductive coaxial nanotubes of molecularly connected electron donor and acceptor layers. Science. 2006;314:1761-4. 
74. Yamamoto Y, Fukushima T, Saeki A, Seki S, Tagawa S, Ishii N, et al. Molecular engineering of coaxial donor-acceptor heterojunction by coassembly of two different hexabenzocoronenes: graphitic nanotubes with enhanced photoconducting properties. J Am Chem Soc. 2007;129:9276-7.

75. Yamamoto Y, Jin W, Fukushima T, Minari T, Tsukagoshi K, Saeki A, et al. Charge transport properties of hexabenzocoronene nanotubes by field effect: influence of the oligoether side chains on the mobility. Chem Lett. 2009;38:888-9.

76. He Y, Yamamoto Y, Jin W, Fukushima T, Saeki A, Seki S, et al. Hexabenzocoronene graphitic nanotube appended with dithienylethene pendants: photochromism for the modulation of photoconductivity. Adv Mater. 2010;22:829-32.

77. Zhang W, Jin W, Fukushima T, Saeki A, Seki S, Aida T. Supramolecular linear heterojunction composed of graphite-like semiconducting nanotubular segments. Science. 2011;334:340-3.

78. Saeki A, Yamamoto Y, Koizumi Y, Fukushima T, Aida T, Seki S. Photoconductivity of self-assembled hexabenzocoronene nanotube: insight into the charge carrier mobilities on local and long-range scales. J Phys Chem Lett. 2011;2:2549-54.

79. Yagai S, Goto Y, Lin X, Karatsu T, Kitamura A, Kuzuhara D, et al. Self-organization of hydrogen-bonding naphthalene chromophores into J-type nanorings and H-type nanorods: impact of regioisomerism. Angew Chem Int Ed. 2012;51:6643-7.

80. Lin X, Hirono M, Seki T, Kurata H, Karatsu T, Kitamura A, et al. Covalent modular approach for dimension-controlled selforganization of perylene bisimide dyes. Chem Eur J. 2013;19: 6561-5.

81. Nakada A, Saeki A, Higashi M, Kageyama H, Abe R. Two-step synthesis of Sillén-Aurivillius type oxychlorides to enhance their photocatalytic activity for visible-light-induced water splitting. J Mater Chem A. 2018;6:10909-17.

82. Carini M, Marongiu M, Strutyński K, Saeki A, Melle-Franco M, Mateo-Alonso A. Hooking together sigmoidal monomers into supramolecular polymers. Angew Chem Int Ed. 2019;58: 15788-92.

83. Martínez-Abadía M, Stoppiello CT, Strutynski K, Lerma-Berlanga B, Martí-Gastaldo C, Saeki A, et al. A wavy two-dimensional covalent organic framework from core-twisted polycyclic aromatic hydrocarbons. J Am Chem Soc. 2019;141:14403-10.

84. Kamakura Y, Chinapang P, Masaoka S, Saeki A, Ogasawara K, Nishitani SR, et al. Semiconductive nature of lead-based metal-organic frameworks with three-dimensionally extended sulfur secondary building units. J Am Chem Soc. 2020;142: 27-32.

85. Prasanthkumar S, Saeki A, Seki S, Ajayaghosh A. Solution phase epitaxial self-assembly and high charge-carrier mobility nanofibers of semiconducting molecular gelators. J Am Chem Soc. 2010;132:8866-7.

86. Babu SS, Hollamby MJ, Aimi J, Ozawa H, Saeki A, Seki S, et al. Nonvolatile liquid anthracenes for facile full-colour luminescence tuning at single blue-light excitation. Nat Commun. 2013;4:1969.

87. Martínez-Abadía M, Antonicelli G, Saeki A, Mateo-Alonso A. Readily processable hole-transporting peropyrene gels. Angew Chem Int Ed. 2018;57:8209-13.

88. Ghosh A, Yoshida M, Suemori K, Isago H, Kobayashi N, Mizutani Y, et al. Soft chromophore featured liquid porphyrins and their utilization toward liquid electret applications. Nat Commun. 2019;10:4210.

89. Saeki A, Ohsaki S, Seki S, Tagawa S. Electrodeless determination of charge carrier mobility in poly(3-hexylthiophene) films incorporating perylenediimide as photoconductivity sensitizer and spectroscopic probe. J Phys Chem C. 2008;112:16643-50.

90. Saeki A, Ohsaki S, Koizumi Y, Seki S, Tagawa S. Impact of side-chain length on alternating current mobility of charge carriers in regioregular poly(3-alkylthiophene) films. Synth Met. 2009;159:1800-3.

91. Gosztola D, Niemczyk MP, Svec W, Lukas AS, Wasielewski MR. Excited doublet states of electrochemically generated aromatic imide and diimide radical anions. J Phys Chem A. 2000;104:6545-51.

92. Saeki A, Tsuji M, Seki S. Direct evaluation of intrinsic optoelectronic performance of organic photovoltaic cells with minimizing impurity and degradation effects. Adv Energy Mater. 2011;1:661-9.

93. Yoshikawa S, Saeki A, Saito M, Osaka I, Seki S. On the role of local charge carrier mobility in the charge separation mechanism of organic photovoltaics. Phys Chem Chem Phys. 2015;17: 17778-84.

94. Deibel C, Strobel T, Dyakonov V. Origin of the efficient polaron-pair dissociation in polymer-fullerene blends. Phys Rev Lett. 2009;103:036402.

95. Burke TM, McGehee MD. How high local charge carrier mobility and an energy cascade in a three-phase bulk heterojunction enable $>90 \%$ quantum efficiency. Adv Mater. 2014;26: 1923-8.

96. Guo J, Ohkita H, Yokoya S, Benten H, Ito S. Bimodal polarons and hole transport in poly(3-hexylthiophene):fullerene blend films. J Am Chem Soc. 2010;132:9631-7.

97. Tsuji M, Saeki A, Koizumi Y, Matsuyama N, Vijayakumar C, Seki S. Benzobisthiazole as weak donor for improved photovoltaic performance: microwave conductivity technique assisted molecular engineering. Adv Funct Mater. 2014;24:28-36.

98. Saeki A, Tsuji M, Yoshikawa S, Gopal A, Seki S. Boosting photovoltaic performance of a benzobisthiazole based copolymer: a device approach using a zinc oxide electron transport layer. J Mater Chem A. 2014;2:6075-80.

99. Gopal A, Saeki A, Ide M, Seki S. Fluorination of benzothiadiazole-benzobisthiazole copolymer leads to additivefree processing with meliorated solar cell performance. ACS Sustain Chem Eng. 2014;2:2613-22.

100. Al-Naamani E, Gopal A, Ide M, Osaka I, Saeki A. Exploring alkyl chains in benzobisthiazole-naphthobisthiadiazole polymers: impact on solar-cell performance, crystalline structures, and optoelectronics. ACS Appl Mater Interfaces. 2017;9: 37702-11.

101. Curtarolo S, Hart GLW, Nardelli MB, Mingo N, Sanvito S, Levy O. The high-throughput highway to computational materials design. Nat Mater. 2013;12:191-201.

102. Takahashi K, Tanaka Y. Materials informatics: a journey towards material design and synthesis. Dalton Trans. 2016;45: 10497-9.

103. Dral PO. Quantum chemistry in the age of machine learning. J Phys Chem Lett. 2020;11:2336-47.

104. Saeki A, Kranthiraja K. A high throughput molecular screening for organic electronics via machine learning: present status and perspective. Jpn J Appl Phys. 2020;59:SD0801.

105. Shimata Y, Ide M, Tashiro M, Katouda M, Imamura Y, Saeki A. Charge dynamics at heterojunction between face-on/edge-on PCPDTBT and PCBM bilayer: interplay of donor/acceptor distance and local charge carrier mobility. J Phys Chem C. 2016;120:17887-97.

106. Butler KT, Frost JM, Skelton JM, Svane KL, Walsh A. Computational materials design of crystalline solids. Chem Soc Rev. 2016;45:6138-46.

107. Oliynyk AO, Mar A. Discovery of Intermetallic compounds from traditional to machine-learning approaches. Acc Chem Res. 2018;51:59-68.

108. Jain A, Voznyy O, Sargent EH. High-throughput screening of lead-free perovskite-like materials for optoelectronic applications. J Phys Chem C. 2017;121:7183-7. 
109. Lu S, Zhou Q, Ouyang Y, Guo Y, Li Q, Wang J. Accelerated discovery of stable lead-free hybrid organic-inorganic perovskites via machine learning. Nat Commun. 2018;9:3405.

110. Li L, You Y, Hu S, Shi Y, Zhao G, Chen C, et al. Electronic transport of organic-inorganic hybrid perovskites from firstprinciples and machine learning. Appl Phys Lett. 2019;114:083102.

111. Altae-Tran H, Ramsundar B, Pappu AS, Pande V. Low data drug discovery with one-shot learning. ACS Cent Sci. 2017;3:283-93.

112. Korotcov A, Tkachenko V, Russo DP, Ekins S. Comparison of deep learning with multiple machine learning methods and metrics using diverse drug discovery data sets. Mol Pharmaceutics. 2017;14:4462-75.

113. Sanchez-Lengeling B, Aspuru-Guzik A. Inverse molecular design using machine learning: generative models for matter engineering. Science. 2018;361:360-5.

114. Friederich P, Fediai A, Kaiser S, Konrad M, Jung N, Wenzel W. Toward design of novel materials for organic electronics. Adv Mater. 2019;31:1808256.

115. Gu GH, Noh J, Kim I, Jung Y. Machine learning for renewable energy materials. J Mater Chem A. 2019;7:17096-117.

116. Yang J, De S, Campbell JE, Li S, Ceriotti M, Day GM. Largescale computational screening of molecular organic semiconductors using crystal structure prediction. Chem Mater. 2018;30:4361-71.

117. Musil F, De S, Yang J, Campbell JE, Day GM, Ceriotti M. Machine learning for the structure-energy-property landscapes of molecular crystals. Chem Sci. 2018;9:1289-300.

118. Shu Y, Levine BG. Simulated evolution of fluorophores for light emitting diodes. J Chem Phys. 2015;142:104104.

119. Gómez-Bombarelli R, Aguilera-Iparraguirre J, Hirzel TD, Duvenaud D, Maclaurin D, Blood-Forsythe MA, et al. Design of efficient molecular organic light-emitting diodes by a highthroughput virtual screening and experimental approach. Nat Mater. 2016;15:1120-7.

120. Hachmann J, Olivares-Amaya R, Atahan-Evrenk S, AmadorBedolla C, Sánchez-Carrera RS, Gold-Parker A, et al. The Harvard clean energy project: large-scale computational screening and design of organic photovoltaics on the world community grid. J Phys Chem Lett. 2011;2:2241-51.

121. Nagasawa S, Al-Naamani E, Saeki A. Computer-aided screening of conjugated polymers for organic solar cell: classification by random forest. J Phys Chem Lett. 2018;9:2639-46.

122. Lee $\mathbf{M}-\mathrm{H}$. Insights from machine learning techniques for predicting the efficiency of fullerene derivatives-based ternary organic solar cells at ternary blend design. Adv Energy Mater. 2019;9:1900891.

123. Padula D, Simpson JD, Troisi A. Combining electronic and structural features in machine learning models to predict organic solar cells properties. Mater Horiz. 2019;6:343-9.

124. Zhang G, Zhao J, Chow PCY, Jiang K, Zhang J, Zhu Z, et al. Nonfullerene acceptor molecules for bulk heterojunction organic solar cells. Chem Rev. 2018;118:3447-507.

125. Li S, Li C-Z, Shi M, Chen H. New phase for organic solar cell research: emergence of $\mathrm{Y}$-series electron acceptors and their perspectives. ACS Energy Lett. 2020;5:1554-67.

126. Cui Y, Yao H, Zhang J, Xian K, Zhang T, Hong L, et al. Singlejunction organic photovoltaic cells with approaching $18 \%$ efficiency. Adv Mater. 2020;32:1908205.

127. Liu S, Yuan J, Deng W, Luo M, Xie Y, Liang Q, et al. Highefficiency organic solar cells with low non-radiative recombination loss and low energetic disorder. Nat Photo. 2020;14: $300-5$.

128. Lin Y-C, Lu Y-J, Tsao C-S, Saeki A, Li J-X, Chen C-H, et al. Enhancing photovoltaic performance by tuning the domain sizes of a small-molecule acceptor by side-chain-engineered polymer donors. J Mater Chem A. 2019;7:3072-82.
129. Lin Y-C, Chen C-H, Li R-H, Tsao C-S, Saeki A, Wang H-C, et al. Atom-varied side chains in conjugated polymers affect efficiencies of photovoltaic devices incorporating small molecules. ACS Appl Polym Mater. 2020;2:636-46.

130. Ponseca CS Jr, Savenije TJ, Abdellah M, Zheng K, Yartsev A, Pascher $\mathrm{T}$, et al. Organometal halide perovskite solar cell materials rationalized: ultrafast charge generation, high and microsecond-long balanced mobilities, and slow recombination. J Am Chem Soc. 2014;136:5189-92.

131. Venkatesan NR, Labram JG, Chabinyc ML. Charge-carrier dynamics and crystalline texture of layered Ruddlesden-Popper hybrid lead iodide perovskite thin films. ACS Energy Lett. 2018:3:380-6.

132. Hutter EM, Gélvez-Rueda MC, Osherov A, Bulovic V, Grozema FC, Stranks SD, et al. Direct-indirect character of the bandgap in methylammonium lead iodide perovskite. Nat Mater. 2017;16: 115-20.

133. Semonin OE, Elbaz GA, Straus DB, Hull TD, Paley DW, van der Zande AM, et al. Limits of carrier diffusion in n-type and p-type $\mathrm{CH}_{3} \mathrm{NH}_{3} \mathrm{PbI}_{3}$ perovskite single crystals. J Phys Chem Lett. 2016;7:3510-8.

134. Hutter EM, Eperon GE, Stranks SD, Savenije TJ. Charge carriers in planar and meso-structured organic-inorganic perovskites: mobilities, lifetimes, and concentrations of trap states. J Phys Chem Lett. 2015;6:3082-90.

135. Ishida N, Wakamiya A, Saeki A. Quantifying hole transfer yield from perovskite to polymer layer: statistical correlation of solar cell outputs with kinetic and energetic properties. ACS Photonics. 2016;3:1678-88.

136. Nishikubo R, Ishida N, Katsuki Y, Wakamiya A, Saeki A. Minute-scale degradation and shift of valence-band maxima of $\left(\mathrm{CH}_{3} \mathrm{NH}_{3}\right) \mathrm{SnI}_{3}$ and $\mathrm{HC}\left(\mathrm{NH}_{2}\right)_{2} \mathrm{SnI}_{3}$ perovskites upon air exposure. J Phys Chem C. 2017;121:19650-6.

137. Nakanishi E, Nishikubo R, Wakamiya A, Saeki A. How the mixed cations (guanidium, formamidinium, and phenylethylamine) in tin iodide perovskites affect their charge carrier dynamics and solar cell characteristics. J Phys Chem Lett. 2020;11:4043-51.

138. Nishikubo R, Saeki A. Comparative study of charge carrier dynamics in bismuth-based dimer and double perovskites. J Photopolym Sci Technol. 2019;32:735-40.

139. Iyoda F, Nishikubo R, Wakamiya A, Saeki A. Ag-(Bi, Sb, In, Ga)-I solar cells: impacts of elemental composition and additive on the charge carrier dynamics and crystal structures. ACS Appl Energy Mater. 2020. (In press). https://doi.org/10.1021/acsaem. 0c00628.

140. Nishikubo R, Kanda H, García-Benito I, Molina-Ontoria A, Pozzi G, Asiri AM, et al. Optoelectronic and energy level exploration of bismuth and antimony-based materials for leadfree solar cells. Chem Mater. 2020;32:6416-24.

141. Yamada K, Suzuki H, Abe R, Saeki A. Complex photoconductivity reveals how the nonstoichiometric $\mathrm{Sr} / \mathrm{Ti}$ affects the charge dynamics of a $\mathrm{SrTiO}_{3}$ photocatalyst. J Phys Chem Lett. 2019;10:1986-91.

142. Suzuki H, Kunioku H, Higashi M, Tomita O, Kato D, Kageyama $\mathrm{H}$, et al. Lead bismuth oxyhalides $\mathrm{PbBiO}_{2} \mathrm{X}(\mathrm{X}=\mathrm{CI}, \mathrm{Br})$ as visible-light-responsive photocatalysts for water oxidation: role of lone-pair electrons in valence band engineering. Chem Mater. 2018;30:5862-9.

143. Suzuki H, Higashi M, Kunioku H, Abe R, Saeki A. Photoconductivity-lifetime product correlates well with the photocatalytic activity of oxyhalides $\mathrm{Bi}_{4} \mathrm{TaO}_{8} \mathrm{Cl}$ and $\mathrm{PbBiO}_{2} \mathrm{Cl}$ : an approach to boost their $\mathrm{O}_{2}$ evolution rates. ACS Energy Lett. 2019;4:1572-8.

144. Kittel C. Introduction to solid state physics. Hoboken, NJ: John Wiley \& Sons; 1996. 
145. Eisch JJ. Fifty years of Ziegler-Natta polymerization: from serendipity to science. A personal account. Organometallics. 2012;31:4917-32.

146. Grimes RN. Synthesis and serendipity in boron chemistry: a 50 year perspective. J Organomet Chem. 2013;747:4-15.

147. Song H, Zhan X, Li D, Zhou Y, Yang B, Zeng K, et al. Rapid thermal evaporation of $\mathrm{Bi}_{2} \mathrm{~S}_{3}$ layer for thin film photovoltaics. Sol Energy Mater Sol Cells. 2016;146:1-7.

148. Martinez L, Bernechea M, De Arquer FPG, Konstantatos G. Near IR-sensitive, non-toxic, polymer/nanocrystal solar cells employing $\mathrm{Bi}_{2} \mathrm{~S}_{3}$ as the electron acceptor. Adv Energy Mater. 2011;1:1029-35.

149. Bernechea M, Cao Y, Konstantatos G. Size and bandgap tunability in $\mathrm{Bi}_{2} \mathrm{~S}_{3}$ colloidal nanocrystals and its effect in solution processed solar cells. J Mater Chem A. 2015;3:20642-8.
150. Moreno-García H, Messina S, Calixto-Rodriguez M, Martínez H. Physical properties of chemically deposited $\mathrm{Bi}_{2} \mathrm{~S}_{3}$ thin films using two post-deposition treatments. Appl Surf Sci. 2014;311:729-33.

151. Raut SS, Dhobale JA, Sankapal BR. SILAR deposited $\mathrm{Bi}_{2} \mathrm{~S}_{3}$ thin film towards electrochemical supercapacitor. Phys E. 2017;87: 209-12.

152. Khadraoui M, Benramdane N, Miloua R, Mathieu C, Bouzidi A, Sahraoui K. Optical properties of sprayed $\mathrm{Bi}_{2} \mathrm{~S}_{3}$ nanocrystalline thin film. Solid State Commun. 2015;9:1167-70.

153. Han Q, Chen J, Yang X, Lu D, Wang X. Preparation of uniform $\mathrm{Bi}_{2} \mathrm{~S}_{3}$ nanorods using xanthate complexes of bismuth (III). J Phys Chem C. 2007;111:14072-7.

154. Nishikubo R, Saeki A. Solution-processed $\mathrm{Bi}_{2} \mathrm{~S}_{3}$ photoresistor film to mitigate a trade-off between morphology and electronic properties. J Phys Chem Lett. 2018;9:5392-9.

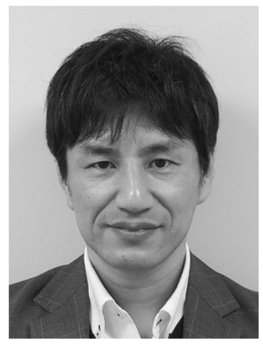

Akinori Saeki received B. Eng. and M. Eng. degrees in nuclear engineering from Osaka University in 1999 and 2001, respectively. He received Dr Eng. in applied chemistry from Osaka University in 2007. He had been an assistant professor at The Institute of Scientific and Industrial Research, Osaka University, in 2003-2009, an assistant professor (tenuretrack) in 2010-2014, and an associate professor in 2014-2019 at the Graduate School of Engineering, Osaka University. He had joined in JST-PRESTO research programs of "Photoenergy conversion systems and materials for the nextgeneration solar cells" in 2009-2013 and "Materials Informatics" in 2015-2019. He is currently a professor at Graduate School of Engineering, Osaka University (2019-present). His research interest is in nanometer-scale dynamics of chemical intermediates in condensed matters such as organic semiconductors, organic liquids, and organic-inorganic hybrid materials. 